\author{
VERA PASCHON
}

\title{
BLOQUEIO DO ACOPLAMENTO CELULAR APÓS TRAUMA MECÂNICO NA RETINA ALTERA A DISTRIBUIÇÃO DE CÉLULAS EM APOPTOSE
}

Tese apresentada ao Programa de PósGraduação em Fisiologia Humana do Instituto de Ciências Biomédicas da Universidade de São Paulo, para obtenção do Título de Doutor em Ciências. 


\section{VERA PASCHON}

\section{BLOQUEIO DO ACOPLAMENTO CELULAR APÓS TRAUMA MECÂNICO NA RETINA ALTERA A DISTRIBUIÇÃO DE CÉLULAS EM APOPTOSE}

Tese apresentada ao Programa de PósGraduação em Fisiologia Humana do Instituto de Ciências Biomédicas da Universidade de São Paulo, para obtenção do Título de Doutor em Ciências.

Área de Concentração: Fisiologia Humana

Orientador: Prof. Dr. Alexandre Hiroaki Kihara

Versão original 
DADOS DE CATALOGAÇÃO NA PUBLICAÇÃO (CIP)

Serviço de Biblioteca e Informação Biomédica do

Instituto de Ciências Biomédicas da Universidade de São Paulo

(C) reprodução total

Paschon, Vera.

Bloqueio do acoplamento celular após trauma mecânico na retina altera a distribuição de células em apoptose / Vera Paschon. -- São Paulo, 2013.

Orientador: Prof. Dr. Alexandre Hiroaki Kihara.

Tese (Doutorado) - Universidade de São Paulo. Instituto de Ciências Biomédicas. Departamento de Fisiologia e Biofísica. Área de concentração: Fisiologia Humana. Linha de pesquisa:

Neurocomunicação celular.

Versão do título para o inglês: Blockade of cell coupling after mechanical trauma in the retina alters scaterring of apoptosis.

1. Retina 2. Conexina 3. Apoptose 4. Caspases 5. Bloqueadores de JCs 6. Neurodegeneração I. Kihara, Prof. Dr. Alexandre Hiroaki II. Universidade de São Paulo. Instituto de Ciências Biomédicas.

Programa de Pós-Graduação em Fisiologia Humana III. Título. 
Candidato(a):

Título da Tese:

Orientador(a):

\section{Vera Paschon.}

Bloqueio do acoplamento celular após trauma mecânico na retina altera a distribuição de células em apoptose.

A Comissão Julgadora dos trabalhos de Defesa da Tese de Doutorado, em sessão pública realizada a ... considerou
( ) Aprovado(a)
( ) Reprovado(a)
Examinador(a): Assinatura:
Nome:
Instituição:
Examinador(a): Assinatura:
Nome:
Instituição:
Examinador(a): Assinatura:
Nome:
Instituição:
Examinador(a): Assinatura:
Nome:
Instituição:

Presidente: Assinatura:

Nome:

Instituição: 


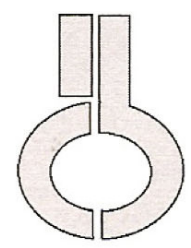

e-mail: cep@icb.usp.br

\section{Certificado}

Certificamos que o protocolo registrado sob $n^{\circ} \mathbf{2 0}$ nas fls. 67 do livro 02 para uso de animais em experimentaçāo, sob a responsabilidade do $\operatorname{Prof}(a) \operatorname{Dr}(a)$ Luiz Roberto G.Britto, Coordenador(a) da Linha de pesquisa Acoplamento celular no arco da vida: desenvolvimento, adaptação e degeneração do sistema nervoso do qual participou(aram) o(s) alunos Caroline Margonato Cardoso, Guilherme Shigueto Villar Higa, Thais Barbosa, Vera Paschon, e o pesquisador Alexandre Hiroaki Kihara, está de acordo com os Principios Éticos de Experimentação Animal adotaco pela Sociedade Brasileira de Ciência de Animais de Laboratório (SBCAL) e foi aprovado pela COMISSÃO DE ÉTICA EM EXPERIMENTAÇÃO ANIMAL (CEEA) em 05.03.09, com validade de 3 anos.

São Paulo, 10 de março de 2009.

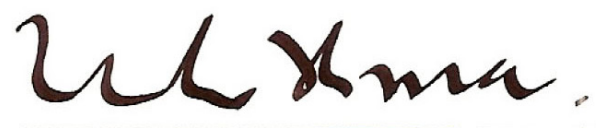

Prof.Dr.WOTHAN TAVARES DE LIMA

Coordenador CEEA - ICB/USP

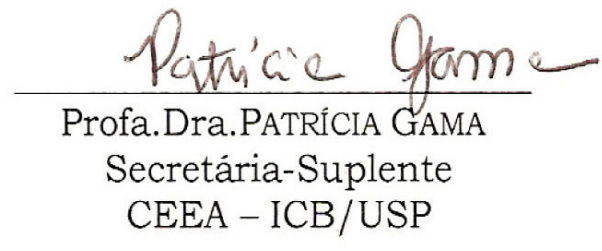




\section{Of.CEUA.008.12}

WTL/mcgn

São Paulo, 17 de fevereiro de 2012.

REF.: Protocolo n 020/09.

"Acoplamento celular no arco da vida: desenvolvimento, adaptação e degeneração do sistema nervoso"

Prezado Professor,

Informo que a sua licença para uso de animais em experimentação, constante no protocolo em epígrafe, foi prorrogada até 05.03.2015.

Reitero que havendo alteração de metodologia e inserção de novos alunos ao projeto de pesquisa vinculado à referida licença a CEUA/ICB deverá ser informada.

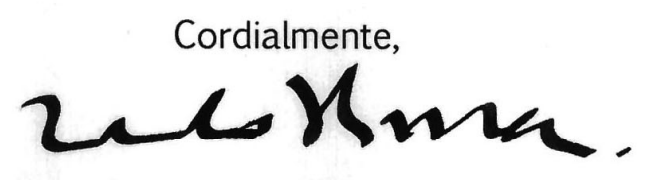

Prof. Dr. WOTHAN TAVARES DE LIMA

Coordenador - CEUA-ICB/ /USP

IItmo.Sr.

Prof Dr. LUIZ ROBERTO GIORGETTI DE BRITO

Departamento de Fisiologia e Biofísica

Instituto de Ciências Biomédicas - USP 
"Ao meu Deus, Senhor de todo meu coração, por me capacitar com o fôlego de vida".

"Ao meu querido esposo Eduardo, pela força, carinho e amor. E por me ensinar a ser uma pessoa melhor, me incentivando a lutar incansavelmente pelos meus sonhos".

"Aos meus pais Edna e Ailton e meus irmãos Ivana e Danilo, por acreditarem na minha capacidade e por incentivarem minhas escolhas profissionais". 


\section{AGRADECIMENTOS}

Durante estes 4 anos de preparação e execução deste trabalho tive 0 privilégio de caminhar lado a lado com pessoas que tiveram grande importância para minha formação acadêmica e para que eu cumprisse meus objetivos e metas traçados. Pessoas que não cruzaram simplesmente meu caminho, mas que entraram na minha vida para sempre e deixaram grandes marcas. Cada um teve uma participação pequena ou grande, mas de fundamental importância nesta caminhada. Esse apoio veio na forma de conselhos, discussões, críticas, colaborações, estudos, auxílios nos experimentos e muito mais. Assim, eu gostaria de agradecer de coração a todos que, de alguma forma, tiveram participação durante esta fase tão importante da minha vida.

Agradeço primeiramente a Deus, meu refúgio e fortaleza, pela sabedoria e inteligência. Por ter me mostrado que com fé podemos atravessar as mais altas barreiras. Por ter me dado vitória em cada passo alçado e força para seguir adiante.

Ao Professor Alexandre H. Kihara pela oportunidade de poder fazer pesquisa de alta qualidade em um laboratório que ajudamos a construir desde as primeiras pipetas até o que é hoje. Por sempre instigar meu raciocínio com discussões calorosas e empolgantes, fazendo crescer em mim a sede de buscar 0 conhecimento através da pesquisa.

A todos os alunos de pós-doutorado, pós-graduação e graduação de nosso laboratório. Pela alegria, pelos bons momentos juntos, pelas comemorações, pelo apoio intelectual, discussões filosóficas, ajuda prática e pelas contribuições científicas.

Aos técnicos que já passaram por nosso laboratório e as técnicas Vanessa e Izabella, que atualmente nos suportam tecnicamente, se esforçando para não deixar faltar tampão, lâminas gelatinizadas, PFA ou sacarose.

À Professora Jean Jiang da Universidade do Texas, Estados Unidos pelo apoio e colaboração internacional, enviando anticorpos e participando de parte dos nossos trabalhos. E por me receber em seu laboratório para realizar um estágio. 
À todos os professores e alunos que frequentam o laboratório de Neurobiologia Celular, dividindo o espaço, reagente e equipamentos. Pela paciência, apoio e alegria. Muitas vezes um simples sorriso diz muita coisa.

Aos meus pais, verdadeiros educadores que sempre investiram no meu crescimento intelectual, por terem acreditado que eu poderia chegar onde estou e por todo apoio e amor.

Agradeço de forma especial ao meu esposo Eduardo Cordeiro, por ter se tornado um exemplo de vida para mim. Sempre estendeu a mão quando percebia que eu poderia tropeçar e esteve ao meu lado sempre que eu precisei, me incentivando e acreditando em mim. Obrigada por me ajudar a conquistar meus sonhos e juntos traçarmos nossa vida!!!

À FAPESP, CNPq e UFABC pelo auxílio financeiro.

Obrigada!!! 
"A verdadeira viagem de descobrimento não consiste em procurar novas paisagens, mas em ter novos olhos". (Marcel Proust) 


\section{RESUMO}

Paschon V. Bloqueio do acoplamento celular após trauma mecânico na retina altera a distribuição de células em apoptose [tese (Doutorado em Fisiologia Humana)]. São Paulo: Instituto de Ciências Biomédicas, Universidade de São Paulo; 2013.

Considerando os avanços recentes no desenvolvimento de medicamentos e tratamentos, a neuroproteção se destaca como um dos tópicos mais relevantes aplicados à neurociência. Evidências indicam que as conexinas (Cx) nos canais de junções comunicantes (JCs) estão envolvidas na neurodegeneração após a lesão. Estudos utilizando modelos de animais KO para Cx apresentam resultados contraditórios em relação ao papel do acoplamento na neuroproteção. Escolhemos analisar o papel das Cxs a partir do trauma mecânico na retina, modelo que permite a definição espacial e temporal da lesão, com elevada reprodutibilidade, distinguindo-se o foco, da penumbra e das áreas adjacentes, além de gerar gradiente de concentração de células apoptóticas do foco para as regiões adjacentes à lesão. Nossos resultados mostraram que as Cx36 e Cx43 tiveram regulação distinta da expressão gênica e níveis proteicos ao longo da neurodegeneração. O padrão de distribuição da Cx36 não se alterou ao longo dos tempos de lesão, mas a Cx43 apresentou desorganização e aumento da imunorreatividade, principalmente após 7 dias. Concomitantemente, a proteína fibrilar glial (GFAP) também teve maior imunorreatividade após 7 dias, indicando gliose reativa decorrente da lesão. A Cx36 foi observada nas proximidades de núcleos apoptóticos, revelando a presença desta proteína em células durante o processo de apoptose. Nossos resultados também mostraram que células amácrinas apoptóticas encontram-se acopladas a células vizinhas saudáveis por $\mathrm{C} \times 36$. O papel funcional do acoplamento celular foi avaliado empregando bloqueadores e abridores de JCs pelo ensaio de lactato desidrogenase (LDH), método in vitro para verificar a viabilidade/morte de células. Carbenoxolone (CBX), bloqueador de JCs de amplo espectro, reduziu a liberação de LDH após 4 horas, enquanto a quinina, bloqueador específico de canais de Cx36, diminuiu a liberação de LDH após 1 hora de aplicação. A análise da distribuição de núcleos TUNEL-positivos confirmou que a utilização de bloqueadores de JCs reduz a propagação da apoptose. Após o bloqueio da comunicação por JCs durante a neurodegeneração com quinina, mas não com $\mathrm{CBX}$, observamos diminuição na expressão tanto de caspases iniciais quanto efetoras. Mais importante, nossos resultados revelaram que o controle direto da permeabilidade de canais de JCs pode participar de estratégias de neuroproteção destinadas ao tratamento da neurodegeneração aguda.

Palavras-chave: Retina. Conexina. Apoptose. Caspases. Bloqueadores de JCs. Neurodegeneração. 


\begin{abstract}
Paschon V. Blockade of cell coupling after mechanical trauma in the retina alters scattering of apoptosis [Ph. D. thesis (Human Physiology)]. São Paulo: Instituto de Ciências Biomédicas, Universidade de São Paulo; 2013.

Considering the recent advances in drug development and delivery, neuroprotection stands out as one of the most pursued hot topics in applied neurosciences. Accruing evidence indicates that connexin (Cx) channels in the gap junctions (GJ) are involved in neurodegeneration after injury. However, studies using $\mathrm{KO}$ animal models endowed apparently contradictory results in relation to the role of coupling in neuroprotection. We choose analyze the role of $\mathrm{Cx}$-mediated communication in focal lesion induced by mechanical trauma in the retina, a model that allows spatial and temporal definition of the lesion with high reproducibility, permitting visualization of the focus, penumbra and adjacent areas, and generate a concentration gradient of cells in apoptosis from the focus to adjacent regions nearby the injury. Our results showed a distinct regulation of gene expression and protein levels for Cx36 and Cx43 throughout the neurodegeneration progress. The Cx36 distribution pattern did not change during the lesion progression, but the $\mathrm{Cx} 43$ showed disorganized pattern and upregulaton after 7 days. At the same period, glial fibrilar protein (GFAP) was upregulated in the lesion focus exposing a reactive gliosis after 7 days. Cx36 was observed close to apoptotic nuclei, revealing the presence of this protein surrounding apoptotic cells. Our results revealed that amacrine cells are coupled with health neighborhood cells by $\mathrm{Cx} 36$. The functional role of cell coupling was assessed employing GJ blockers and openers combined with lactate dehydrogenase (LDH) assay, a direct method for evaluating cell death/viability. Carbenoxolone (CBX), a broad-spectrum GJ blocker, reduced LDH release after 4 hours, whereas quinine, a Cx36-channel specific blocker, decreased LDH release as early as 1 hour. Furthermore, analysis of dying cell distribution confirmed that the use of GJ blockers reduced apoptosis spread. Accordingly, blockade of GJ communication during neurodegeneration with quinine, but not CBX, caused downregulation of initial and effector caspases. To summarize, we observed specific changes in $\mathrm{Cx}$ gene expression and protein distribution during the progress of retinal degeneration, indicating the participation of these elements in acute neurodegeneration processes. More importantly, our results revealed that direct control of GJ channels permeability may take part in reliable neuroprotection strategies aimed to rapid, fast treatment of mechanical trauma.
\end{abstract}

Keywords: Retina. Connexins. Apoptosis. Caspases. GJ Blockers. Neurodegeneration. 


\section{LISTA DE ABREVIATURAS E SIGLAS}

SN - sistema nervoso

MCP - morte celular programada

ROS - espécies reativas de oxigênio

JC - junção comunicante

Cx - conexina

SNC - sistema nervoso central

KO - knockout

RPE - epitélio pigmentado retiniano

PL - camada de fotorreceptores

ONL - camada nuclear externa

OPL - camada plexiforme externa

INL - camada nuclear interna

IPL - camada plexiforme interna

GCL - camada de células ganglionares

NFL - camada de axônios retinianos

PFA - paraformaldeído

PB - tampão fosfato

BS - solução salina tamponada

PI - iodeto de propídio

GFAP - proteína fibrilar glial

PCR - reação em cadeia de polimerase

TUNEL - "terminal deoxynucleotidyl transferase-mediated d-UTP nick end-labeling”

LDH - lactato desidrogenase

CBX - carbenoxolone

TMA - trimetilamina

ChAT - colina-acetiltransferase

E5 - idade embrionária 5

E10 - idade embrionária 10

E15 - idade embrionária 15

P15 - idade pós-natal 15

ex - exemplo 


\section{LISTA DE FIGURAS}

Figura 1- Classificação e eventos moleculares que levam à MCP............... 18

Figura 2- Cx, hemicanal e canal de Cx................................................ 20

Figura 3- Estrutura das JCs........................................................... 21

Figura 4- Gráfico de sensibilidade à voltagem de diferentes Cxs............... 22

Figura 5- Organização molecular das Cxs............................................ 23

Figura 6- Esquema da retina de vertebrados com seus principais tipos celulares e camadas................................................................. 26

Figura 7- Dissecção da retina para experimentos funcionais..................... 34

Figura 8- Expressão gênica e níveis proteicos da Cx36 e da Cx43 após neurodegeneração da retina induzida por trauma mecânico....... 42

Figura 9- Imunofluorescência de Cx36 em secções transversais da retina de pinto após lesões mecânicas

Figura 10- Imunofluorescência de Cx43 em secções transversais da retina de pinto após lesões mecânicas.

Figura 11- Caracterização de gliose reativa decorrente da lesão.

Figura 12- Ensaio de TUNEL em retinas com lesões mecânicas.

Figura 13- Relação espacial entre a Cx36 e núcleos TUNEL-positivos no foco e penumbra da lesão

Figura 14- Expressão de Cx36 em neurônios específicos durante o processo de apoptose.

Figura 15- Avaliação da viabilidade celular utilizando a quantificação de lactato desidrogenase (LDH) liberada pelas retinas lesionadas tratadas com bloqueadores e abridores de JCs

Figura 16- Expressão gênica de caspases em explantes de retinas lesionadas tratados com bloqueadores de JCs.

Figura 17- Ensaio de TUNEL em explantes de retinas tratados com bloqueadores de JCs.

Figura 18- Ensaio de TUNEL em retinas lesionadas com injeção de bloqueadores de JCs. 
1 INTRODUÇÃO.

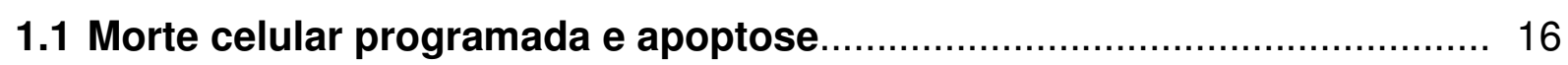

1.2 Junções comunicantes (JCs) e conexinas (Cxs).................................. 19

1.3 Acoplamento celular no sistema nervoso (SN) .................................... 24

1.4 A retina como modelo de estudo do SN............................................... 25

1.5 Acoplamento celular na neurodegeneração........................................... 29

1.6 Justificativa para o estudo............................................................. 30

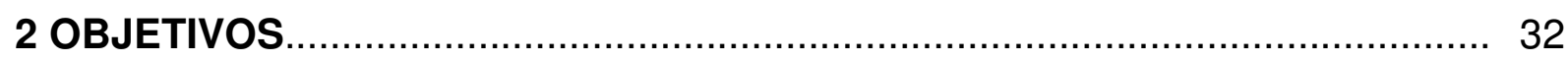

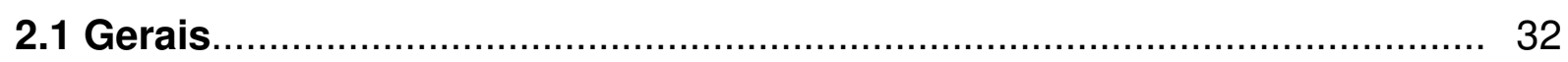

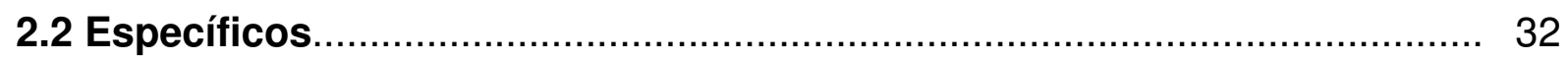

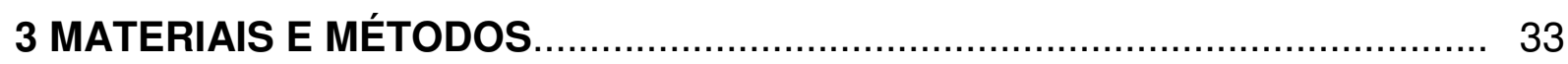

3.1 Padronização do modelo de lesão retiniana.......................................... 33

3.2 Quantificação da expressão gênica de Cxs por PCR em tempo real......... 34

3.3 Quantificação dos níveis proteicos por Western Blot............................... 35

3.4 Caracterização do padrão de distribuição proteica por

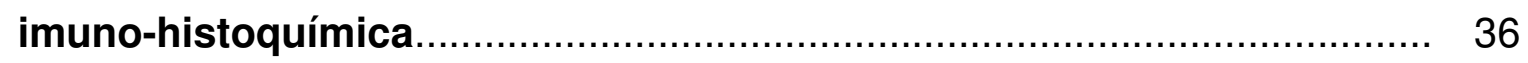

3.5 Avaliação do espalhamento da apoptose por TUNEL.............................. 37

3.6 Experimentos de dupla e tripla marcação com TUNEL............................... 37

3.7 Ensaio de liberação de lactato desidrogenase (LDH) e avaliação

da expressão gênica de caspases.................................................... 38

3.8 Incubação de explantes de retinas lesadas com bloqueadores de JCs

para quantificação do espalhamento da morte celular secundária.......... 39

3.9 Injeção de bloqueadores de JCs in vivo para quantificação

do espalhamento da morte celular secundária...................................... 39

3.10 Análise dos resultados ………................................................. 39

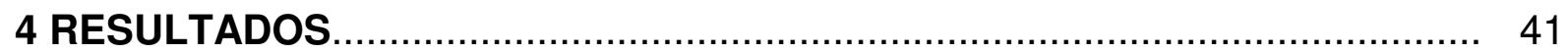

4.1 Caracterização da expressão gênica e níveis proteicos de Cxs na degeneração da retina por trauma mecânico..................................... 41

4.2 Cx36 mantém padrão de distribuição constante durante a

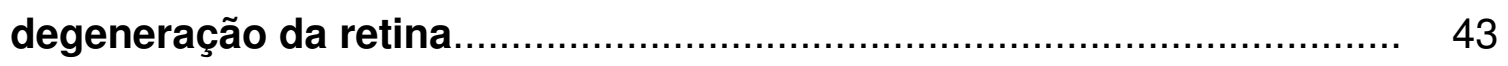

4.3 Cx43 está presente na camada de células ganglionares durante a degeneração da retina 
4.4 Caracterização da gliose reativa no modelo de lesão após 7 dias.

4.5 Pico de apoptose ocorre entre 6 e 24 horas após o trauma mecânico

4.6 Marcação de Cx36 foi observada nas proximidades de células apoptóticas.

4.7 Células amácrinas expressam Cx36 durante o processo de apoptose.

4.8 Bloqueadores de JCs aumentam a viabilidade celular em explantes de retina.

4.9 Bloqueadores de JCs diminuem a expressão gênica de caspases durante a degeneração retiniana.

4.10 Bloqueadores de JCs limitam o espalhamento da apoptose in vitro.

4.11 Injeção intraocular de bloqueadores de JCs afeta o espalhamento da apoptose 60

5 DISCUSSÃO 63

6 CONCLUSÕES 68

REFERÊNCIAS. 69

APÊNDICE A - Artigo A new and reliable guide for studies of neuronal loss based on focal lesions and combinations of in vivo and in vitro approaches.

APÊNDICE B - Artigo Blocking of connexin-mediated communication promotes neuroprotection during acute degeneration induced by mechanical trauma...

APÊNDICE C-Artigo Connexin-mediated communication controls cell proliferation and is essential in retinal histogenesis. 


\section{INTRODUÇÃO}

Considerando os avanços recentes no desenvolvimento de medicamentos e tratamentos, a neuroproteção se destaca como um dos tópicos mais relevantes aplicados à neurociência.

O termo neurodegeneração está relacionado com a perda progressiva da estrutura e função do neurônio, ou ainda, com a morte de neurônios. Lesões no SN, bem como doenças neurodegenerativas, incluindo acidente vascular cerebral, doença de Alzheimer, doença de Parkinson, doença de Huntington, esclerose lateral amiotrófica e esclerose múltipla apresentam características em comum, das quais a mais importante é a perda de neurônios, seja pela perda de função, ou devido a apoptose (Klein, Ackerman, 2003).

\subsection{Morte celular programada e apoptose}

Neurônios, no sistema nervoso adulto, são chamados de células pós-mitóticas por terem a característica de serem terminalmente diferenciados. Este estado implica em duas principais características fisiológicas: diminuição de mecanismos relacionados à divisão celular (Nguyen et al., 2002) e aumento de mecanismos relacionados com a proteção da célula na morte celular programada (MCP), especialmente durante o processo de apoptose (Leist, Jaattela, 2001). Em condições patológicas, sejam agudas ou crônicas associadas com insultos citotóxicos e estresse oxidativo, essas adaptações são perdidas, levando a reentrada no ciclo celular, processo que neste caso antecipa a morte celular (Becker, Bonni, 2005). Os neurônios são altamente sensíveis à ação de mediadores de estresse oxidativo, tais como as espécies reativas de oxigênio (ROS), as quais estão associadas à MCP (Rego, Oliveira, 2003).

A MCP é geralmente definida como uma série de alterações bioquímicas e morfológicas estereotipadas que conduzem à morte celular. Estas características são frequentemente utilizadas para distinguir o caráter "ativo" da MCP, pelo qual as células que morrem são eliminadas seguramente, de forma não inflamatória, diferente da morte celular "passiva" por necrose (Leist, Jaattela, 2001). Sob condições fisiológicas, a MCP é rigorosamente controlada e regula o equilíbrio entre 
a proliferação e a diferenciação tanto durante o desenvolvimento quanto na optimização das células adultas e nas funções dos tecidos (Lockshin, Zakeri, 2004).

Estudos com base no critério da morfologia nuclear dividem a MCP em apoptose clássica, apoptose similar à $\mathrm{MCP}$ e necrose similar à MCP, respectivamente caracterizados por maior condensação da cromatina nuclear, condensação parcial ou periférica, ou ausência de condensação (Jaattela, Tschopp, 2003; Lockshin, Zakeri, 2004) (Figura 1).

Apoptose clássica consiste em pelo menos duas fases, iniciação e execução. Estas conduzem, em última análise, a uma série de eventos morfológicos e bioquímicos resultantes da ativação de proteases de aspartato cisteínadependentes, conhecidas como caspases. As vias canônicas da ativação das caspases durante a iniciação incluem o recrutamento da procaspase-2, procaspase8 e procaspase-10, além de uma via de ativação da mitocôndria, através da qual a caspase- 9 é ativada pela liberação de citocromo C. As duas vias convergem, conduzindo à ativação de procaspase-3 e posteriormente caspases-6 e 7. Essas vias levam à ativação de DNAses que promovem a fragmentação do DNA (Hengartner, 2000), como representado na figura 1.

A apoptose parecida com a MCP é mais ampla do que a apoptose clássica e inclui vias independentes da ativação mitocondrial. Neste contexto, o fator de indução de apoptose (AIF) tem atraído muito interesse porque é o mais conhecido na morte celular independente de caspases (Joza et al., 2001; Susin et al., 1999). Após a permeabilização da membrana mitocondrial externa, o AIF é liberado do espaço intermembrana mitocondrial e translocado para o núcleo, onde se associa em grande escala com a fragmentação do DNA (Susin et al., 1999) (Figura 1).

Na necrose semelhante à MCP, o programa de morte celular é desencadeado por diferentes organelas, como mitocôndrias, lisossomas, retículo endoplasmático e núcleo, e por outras proteases de caspases, entre elas as catepsinas e calpaínas provenientes do lisossoma e do retículo endoplasmático (Figura 1). Os mecanismos moleculares subjacentes à MCP são menos compreendidos, apesar de geralmente acreditar-se que eles representam vias de morte "alternativas" quando as caspases são inibidas (Jaattela, Tschopp, 2003; Lockshin, Zakeri, 2004). 
Figura 1- Classificação e eventos moleculares que levam à MCP.

Caspase-dependent

(a) Classical apoptosis
Caspase-independent

(b) Apoptosis-like PCD (c) Necrosis-like PCD

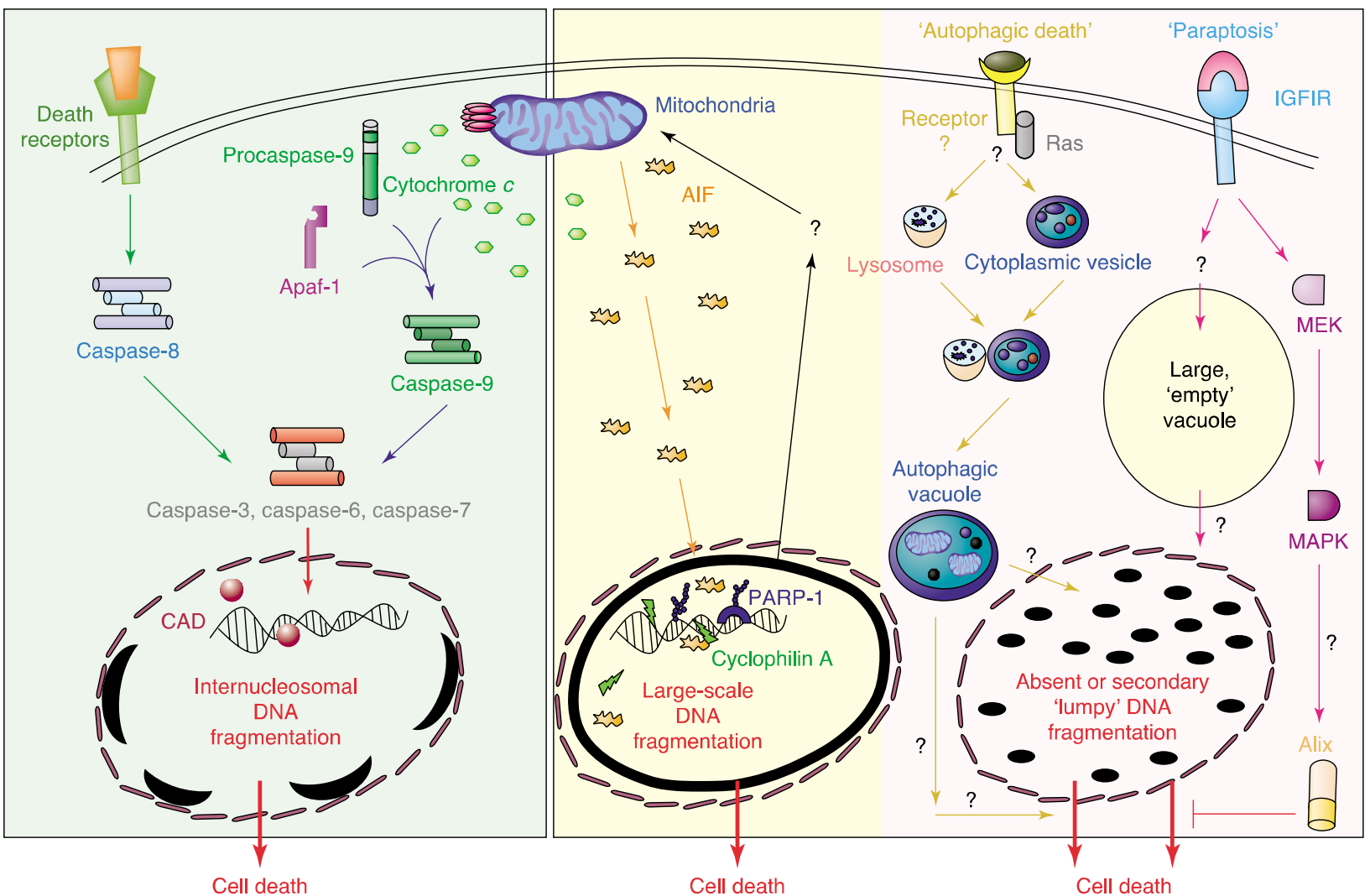

A MCP pode ser dividida em três tipos: $(A)$ apoptose clássica (com grande condensação da cromatina), (B) apoptose semelhante à MCP (com condensação da cromatina parcial e periférica) e (C) necrose semelhante à MCP (sem condensação da cromatina). (A) A apoptose clássica engloba duas vias, ambas acopladas a uma cascata de caspases, que conduzem à ativação de caspases efetoras, incluindo caspase-3, caspase-6, caspase-7. Estas levam ao rompimento do DNA internucleossômico pela ativação de DNAses e endonucleases (CAD). (B) A apoptose semelhante à MCP é mediada por efetores mitocondriais, como o fator de indução de apoptose (AIF). Danos no DNA são detectados por poli-ADP-ribose-polimerase 1 (PARP-1), e um sinal direto ou indireto para a mitocôndria. Isto conduz à libertação de AIF e sua translocação para o núcleo, o qual é então associado à condensação da cromatina e a fragmentação do DNA. (C) A necrose semelhante à MCP é desencadeada pela ativação do receptor de fator de crescimento semelhante à insulina 1 (IGFIR) via proteína quinase (MAPK), e é acompanhada pela formação de grandes vacúolos aparentemente vazios. A outra forma de morte celular por necrose, 'degeneração autofágica', é mediada pela ativação de Ras mutada. Este processo está associado com a formação de lisossomas citoplasmáticos, derivados de vacúolos.

Fonte: Adaptado de Krantic et al., 2005. 


\subsection{Junções comunicantes (JCs) e conexinas (Cxs)}

A comunicação interneuronal rápida é fundamental para a integração e propagação de sinais no sistema nervoso central. Embora a transmissão sináptica química seja o meio de comunicação neuronal mais estudado, estudos sobre a sinalização elétrica direta entre neurônios datam mais de 50 anos (Furshpan, Potter, 1957; Watanabe, 1958) As sinapses elétricas são especializações de membranas de células justapostas chamadas de JCs (Bennett et al., 1991; Goodenough, Revel, 1970), que são compostas de dois hemicanais ou conexônios, formando um canal que permite a comunicação direta com o citoplasma das células vizinhas, como podemos ver na figura 2, proporcionando um caminho intercelular para a difusão de moléculas de até 1.000Da ou moléculas com diâmetro de 10-14nm (Bruzzone, Ressot, 1997; Kumar, Gilula, 1996). Essas moléculas podem ser íons, aminoácidos como glutamato, glicose, metabólitos como ATP, ADP, segundos mensageiros como o AMPc e 0 inositol 1,4,5-trifosfato $\left(\mathrm{IP}_{3}\right)$, além de antígenos e fatores liberados durante a apoptose. Mais recentemente foi proposta a passagem de microRNAs por JCs (Katakowski, Palliser, 2010). Proteínas e ácidos nucléicos aparentemente não atravessam os canais de JCs (Saez et al., 1989). Os hemicanais, por sua vez, são compostos por seis subunidades de proteínas transmembrânicas chamadas conexinas, aproximadamente 20 diferentes isoformas desta proteína foram caracterizadas em seres humanos e roedores (Sohl, Willecke, 2003; Willecke et al., 2002). 
Figura 2- Cx, hemicanal e canal de Cx.

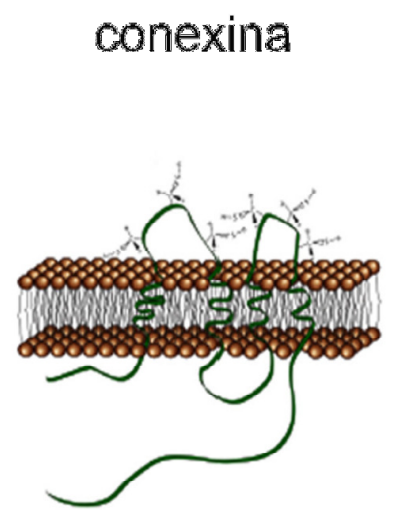

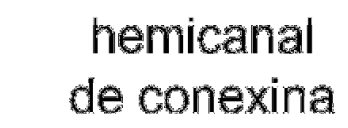

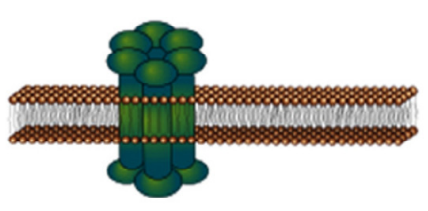

Canal

de conexina

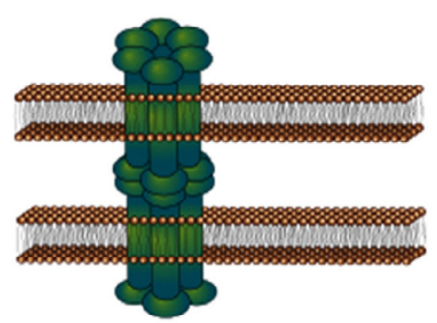

Podemos observar a representação de uma Cx com 4 domínios transmembrânicos, 1 hemicanal formado pelo arranjo de $6 \mathrm{Cxs}$ e 1 canal de JC formado pelo acoplamento de 2 hemicanais de $\mathrm{Cx}$

Fonte: Adaptado de Giaume et al., 2013.

O hemicanal pode ser composto por 1 tipo de conexina sendo denominado canal homomérico ou pode ser composto por diferentes tipos de conexinas, sendo denominado canal heteromérico. Além disso, os canais de JCs podem ser compostos por dois hemicanais formados pelas mesmas conexinas, sendo denominados canais homotípicos ou por dois canais formados por conexinas diferentes sendo denominados heterotípicos. Os canais também podem ser classificados quanto aos tipos celulares acoplados. Canais homólogos são formados por hemicanais de duas células do mesmo tipo, canais heterólogos são formados por hemicanais de duas células de tipos variados (Rozental et al., 2000). 
Figura 3- Estrutura das JCs.

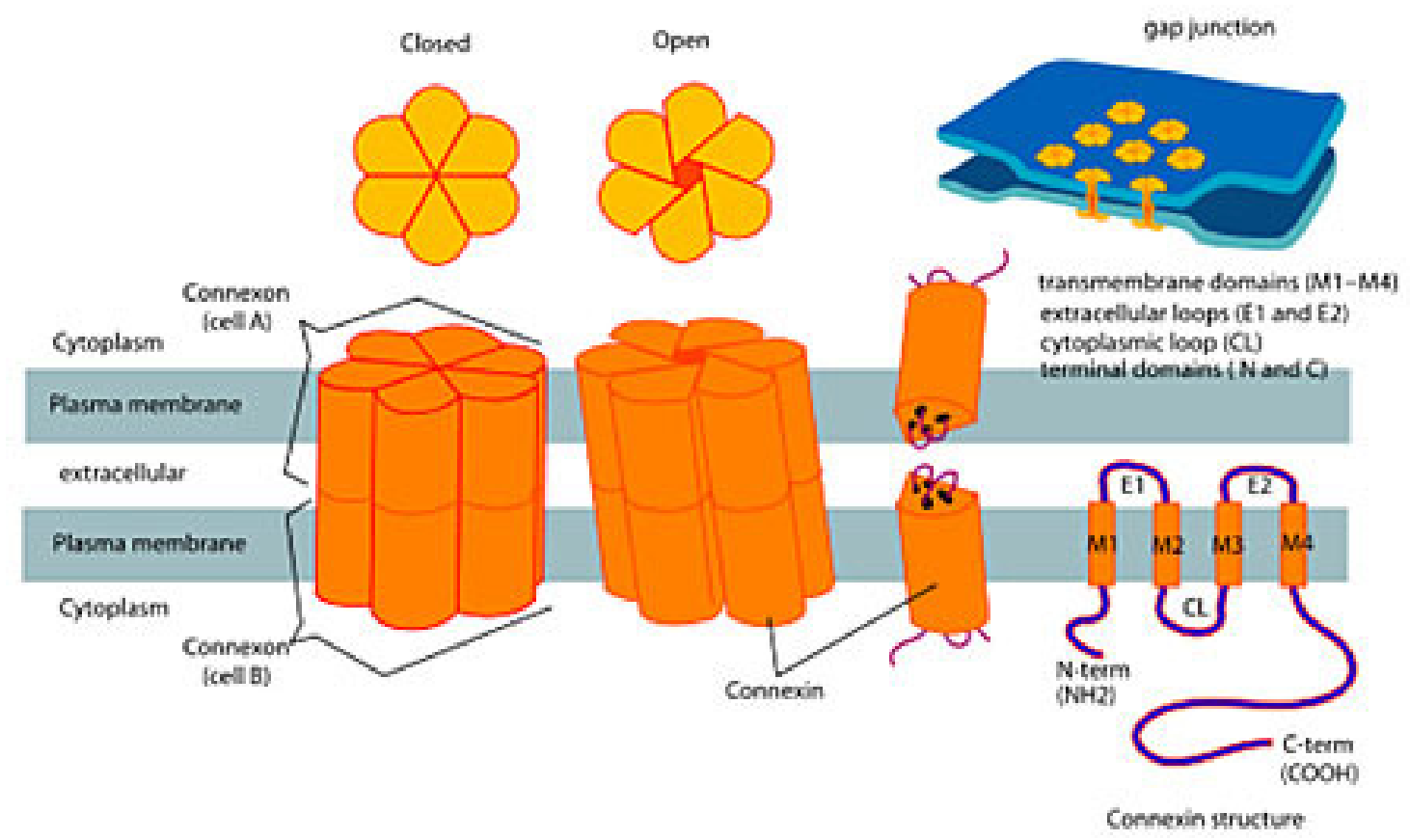

As JCs são formadas entre as membranas opostas de células vizinhas. Hemicanais de células vizinhas se conectam de modo a formar canais condutores entre as duas células. Um largo campo destes canais forma uma placa de JCs. Cada hemicanal, ou conexônio, é composto por seis subunidades de Cxs que são orientadas perpendicularmente às membranas das células, para formar um poro central. Este poro central serve como um canal para íons e moléculas de baixa massa molecular (até $1000 \mathrm{Da}$ ). Os canais formados por Cxs podem encontrar-se no estado conformacional aberto ou fechado, sendo passíveis de modulação por diferentes estímulos, elétricos ou químicos.

Fonte: Adaptado de Higa et al. 2012.

Semelhante aos canais iônicos, a condutância elétrica e a cooperação metabólica das JCs são reguladas por grande número de fatores fisiológicos. As conexinas podem sofrer modificações pós-transcricionais (fosforilação) nas extremidades carbóxi e amino terminais (Lampe, Lau, 2000, 2004) (Figura 3). A fosforilação das Cxs pode ser modulada por proteínas quinases que sofrem regulação de vários fatores, incluindo o complexo $\mathrm{Ca}^{2+}$-calmodulina, AMP cíclico, GMP cíclico, variação de $\mathrm{pH}$, voltagem intercelular de 15 a $90 \mathrm{mV}$, hormônios e neuromoduladores como isoproteranol, dopamina, acetilcolina, ácido $\gamma$-aminobutírico e estrógenos) (Koistinaho et al., 1993; Witkovsky, Schutte, 1991). 
Figura 4- Gráfico de sensibilidade à voltagem de diferentes Cxs.

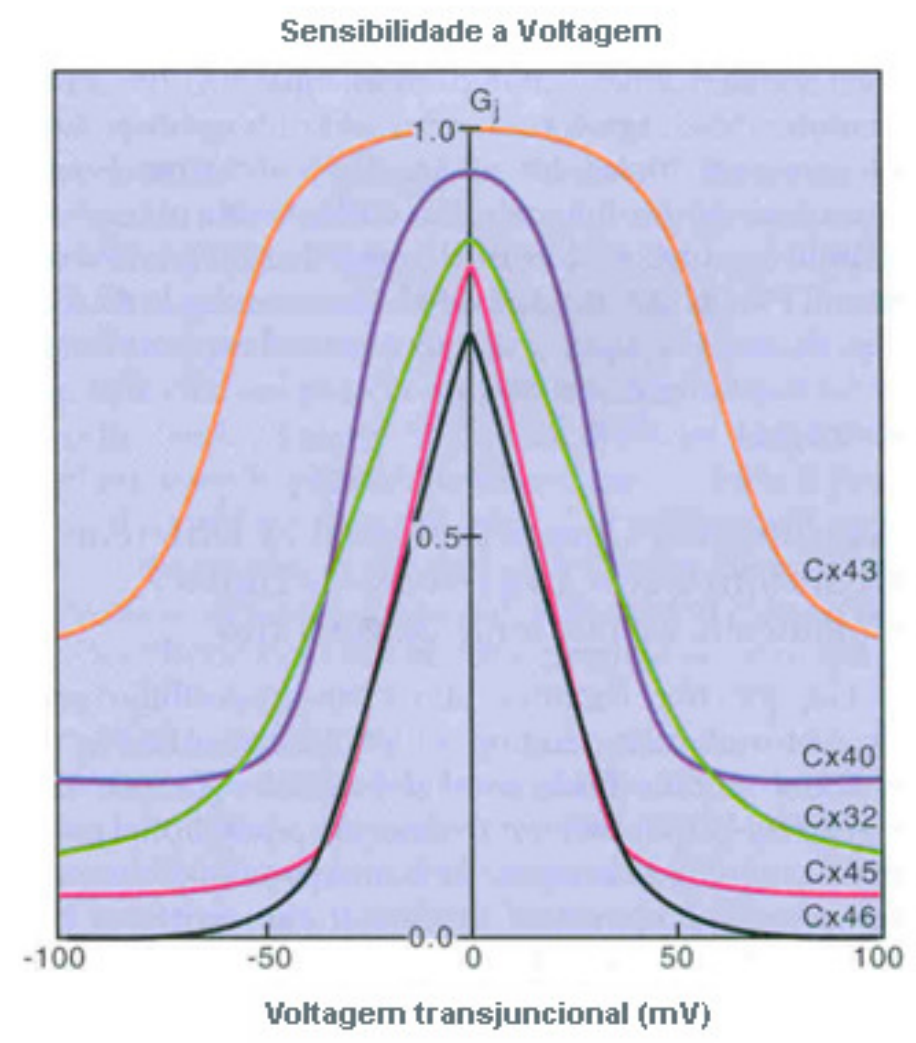

Quando a diferença de voltagem é 0 , ou seja, não há diferença de voltagem de uma célula para a outra, a permeabilidade dos canais é máxima. Quando ocorre variação da voltagem entre as células acopladas, a permeabilidade dos canais tende a diminuir.

Fonte: Adaptado de Zigmond, 1999.

Mudanças sutis no $\mathrm{pH}$ intracelular podem alterar o acoplamento elétrico e metabólico entre neurônios (Church and Baimbridge, 1991; Spray et al., 1981) e células da glia (Giaume et al., 2013). Acidificação geralmente resulta em diminuição da condutância de certas JCs, enquanto que alcalinização faz aumentar a condutância. Finalmente, a maioria das $\mathrm{Cxs}$ é sensível às diferenças de voltagem da membrana (Spray et al., 1979; Srinivas et al., 1999). Os canais de JCs possuem sítios para protonação e ligação de íons $\mathrm{Ca}^{2+} \mathrm{e} \mathrm{Zn}^{2+}$, além de locais específicos para que ocorra fosforilação por proteínas quinases (Yeager, Nicholson, 1996). A transcrição de conexinas e o acoplamento também podem ser regulados pela ação de hormônios, matriz extracelular e condições do ciclo celular.

A condutância total das JCs, definida pela somação espaço-temporal da condutância de cada canal individualmente, é determinada pelo potencial 
transjuncional somado a todos os outros fatores descritos anteriormente (Becker et al., 2002). Cxs específicas estão presentes em diferentes tipos celulares e tecidos, e uma célula isolada pode expressar vários tipos de Cxs. Diferenças entre as JCs podem ser resultantes das diferenças entre as Cxs que formam os canais ou das diferenças entre os tipos celulares acoplados (Bennett et al., 1991).

A expressão diferenciada de Cxs resultando em canais funcionalmente distintos poderia influenciar na difusão de diversas moléculas sinalizadoras (Lo, 1996). Cada Cx possui propriedades específicas quanto à permeabilidade dos canais, à voltagem e à condutância unitária. Enquanto algumas JCs são mais permeáveis a ânions, outras têm preferência por cátions ou apresentam seletividade por carga (Orellana et al., 2009). A expressão de diferentes Cxs em tipos celulares específicos e as regulações durante a histogênese é fundamental para que os processos fisiológicos ocorram. Finalmente, alterações na expressão destas proteínas parecem estar relacionadas à variada gama de processos patológicos (Froes et al., 1999).

Figura 5- Organização molecular das Cxs.

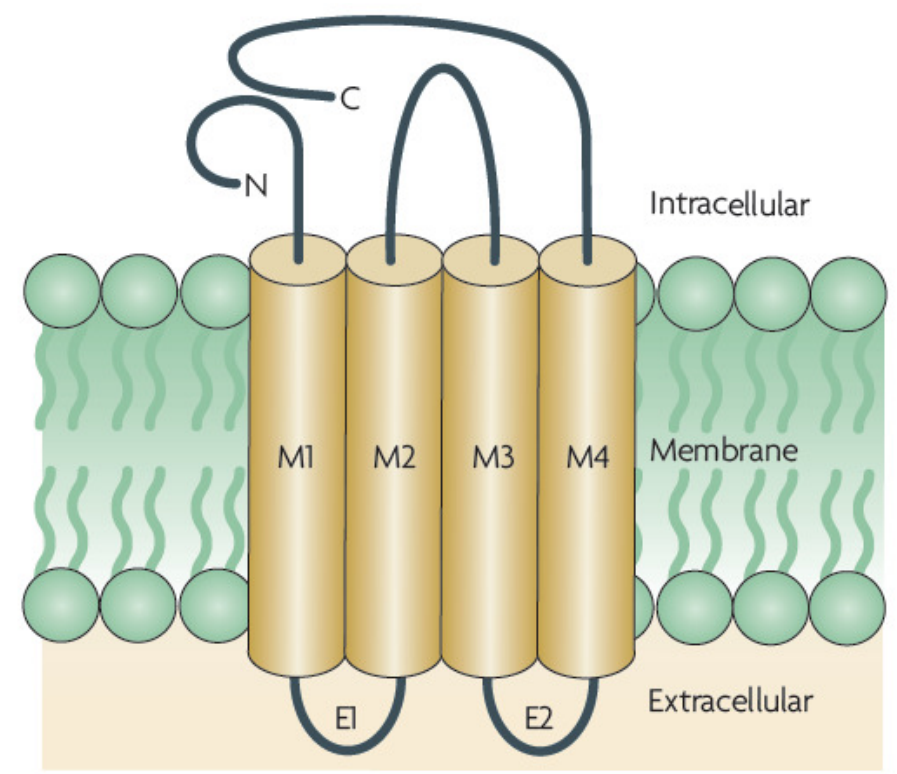

Cxs são proteínas que possuem quatro domínios transmembranares, duas alças extracelulares (E1 e E2) e uma alça intracelular, bem como terminações de carboxila e amina, no citoplasma. Embora os quatro domínios transmembranares (M1-M4) partilhem de uma sequência conservada, importante para a ancoragem na membrana celular, os seus domínios citoplasmáticos variam em comprimento e sequência de aminoácidos. A regulação da estrutura tridimensional da $\mathrm{Cx}$, processo que define a abertura e fechamento dos canais de JCs, é mediada em regiões citoplasmáticas.

Fonte: Adaptado de Bloomfield, Volgyi, 2009. 
Atualmente, aproximadamente 20 tipos de Cxs foram identificados no sistema nervoso de mamíferos. Cada Cx recebe como nome o valor do seu peso molecular em kDa e são divididas em grupos conforme a estrutura proteica. O segmento da molécula entre M2 e M3 forma uma alça intracelular, cujo comprimento e homologia determinam o grupo ao qual cada uma pertence, além disso, o comprimento do segmento carboxi terminal também tem variação nos diferentes grupos de Cxs (Bennett et al., 1991). Quando a alça intracelular e o segmento carboxi terminal são curtos, a Cx é classificada no grupo I ou $\beta$ e neste grupo estão inclusas as Cx26, Cx29, Cx30, Cx31, Cx31.1 e Cx32. As Cxs do grupo II ou $\alpha$ apresentam os seguimentos mais longos que as demais e incluem as Cx33, Cx37, Cx40, Cx43, Cx45, Cx46, Cx47, Cx50 e Cx57 (Bennett et al., 1991). Em adição, a Cx36, que foi descrita recentemente, é classificada como a única $\mathrm{Cx}$ pertencente ao grupo III ou $\mathrm{Y}$ (Rozental et al., 2000).

Em aves, a expressão de Cxs vem sendo cada vez mais estudada: inicialmente foi identificada a expressão das Cx26, Cx32 e Cx43 na retina de pintos (Becker et al., 2002) e mais recentemente, foram descritas também as Cx36, Cx45 e Cx50 (Kihara et al., 2008, Kihara et al., 2009). A Cx36 é responsável pelo acoplamento neuronal e a Cx43 pelo acoplamento glial em mamíferos, o que também foi constatado em estudos em pintinhos (Kihara et al., 2008, Kihara et al., 2009), por isso temos interesse em estudar o papel dessas Cxs no espalhamento da apoptose na retina desses animais.

\subsection{Acoplamento celular no sistema nervoso (SN)}

Existem inúmeras diferenças entre as sinapses químicas e elétricas como, por exemplo, a distância entre as células pré- e pós-sinápticas, que nas sinapses químicas, varia entre 20 e 40 nanômetros $(\mathrm{nm})$, enquanto que nas elétricas essa distância é de 3,5nm. O sentido da transmissão é particularmente diferente nos dois sistemas (unidirecional na química e normalmente bidirecional na elétrica). Os dois tipos de sinapses também apresentam diferenças morfológicas fundamentais: a transmissão química necessita de vesículas pré-sinápticas, zonas ativas e receptores pós-sinápticos, enquanto a sinapse elétrica ocorre por meio de canais inseridos na membrana em pontos específicos que formam as JCs (Zigmond, 1999). 
Embora as sinapses elétricas sejam caracterizadas pela passagem direta de íons entre as células, sua atividade elétrica pode ser sincronizada por potenciais de ação entre neurônios, deflagrados a partir de sinapses químicas (Rozental et al., 2000).

Estudos recentes mostraram que as Cxs não possuem apenas funções dependentes de canais. Elas podem formar hemicanais sem formar acoplamento, permitindo a passagem de moléculas como o ATP ou ADP para o meio externo. As Cxs também podem agir na adesão celular promovendo interações entre proteínas (Orellana et al., 2009), além de agir de outras formas independentes que ainda não foram bem descritas na literatura. Estudos in vitro mostraram que a porção carboxi terminal da Cx43 atua no controle do crescimento celular e da expressão gênica através da interação entre moléculas, e não devido à formação de canais (Theis et al., 2005) Experimentos com bloqueadores de JCs mostraram que o desacoplamento não interfere na diferenciação celular do cristalino de pintos. Neste mesmo estudo, foi sugerido que a porção carboxi terminal da Cx45.6 atua no controle do desenvolvimento independentemente da formação de canais (Jiang and $\mathrm{Gu}, 2005)$.

Além disso, as células gliais acopladas por JCs formam um sincício panglial envolvendo oligodendrócitos e astrócitos, permitindo a manutenção da homeostasia de íons durante a atividade axonal e na degeneração (Nagy, Rash, 2003; Theis et al., 2005).

\subsection{A retina como modelo de estudo do SN}

A retina é um tecido neural com origem mesodérmica, muito utilizada como modelo de estudo do SN por ser um órgão de fácil acesso, com camadas bem definidas formadas alternadamente de corpos celulares e processos de neurônios.

Muitos tipos celulares já foram descritos na retina (Figura 5), como por exemplo, os fotorreceptores que podem ser classificados em cones ou bastonetes dependendo do comprimento de onda que decodificam. Estas células formam a camada nuclear externa (ONL) que é responsável por receber o sinal luminoso e iniciar a transmissão nervosa. As células bipolares em conjunto com as horizontais e as células amácrinas formam a camada nuclear interna (INL) e dão seguimento à decodificação e interação das informações visuais. Entre essas duas camadas de núcleos está situada a camada plexiforme externa (OPL) que concentra os 
processos de fotorreceptores, células bipolares e horizontais. As células ganglionares e algumas células amácrinas deslocadas formam a camada de células ganglionares (GCL). Os axônios das células ganglionares se unem para formar o nervo óptico e a camada de axônios retinianos (NFL) e transmitir a informação captada pela retina ao SNC. Entre a camada nuclear interna e a camada de células ganglionares aparece a camada plexiforme interna (IPL) onde se situam os processos de células bipolares, amácrinas e ganglionares.

Figura 6- Esquema da retina de vertebrados com seus principais tipos celulares e camadas.

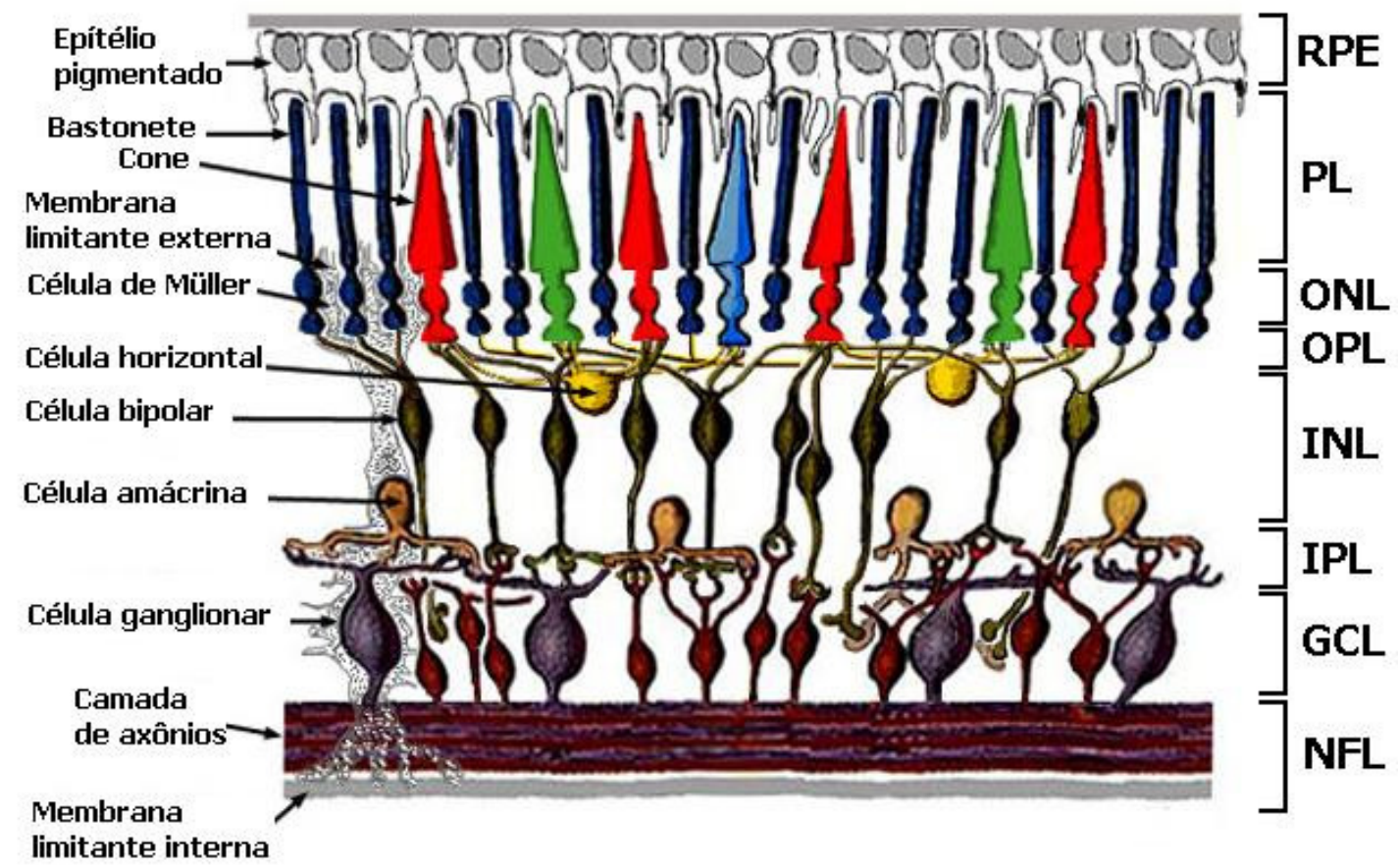

RPE, epitélio pigmentado retiniano; PL, camada de fotorreceptores; ONL, camada nuclear externa; OPL, camada plexiforme externa, INL, camada nuclear interna; IPL, camada plexiforme interna; GCL, camada de células ganglionares; NFL, camada de axônios retinianos.

Fonte: Adaptado de: http://webvision.med.utah.edu. 
O estímulo luminoso começa a ser processado nos fotorreceptores, que promovem a transdução do estímulo eletromagnético em sinal elétrico. Os sinais gerados pelos fotorreceptores são transmitidos às células bipolares, que estão localizadas na camada nuclear interna e em seguida às células ganglionares, situadas na camada de células ganglionares. A informação visual que trafega por esta via de sinalização pode ser modulada pelas células horizontais (nas sinapses entre fotorreceptores e células bipolares) e pelas amácrinas (nas sinapses entre bipolares e ganglionares).

As células retinianas são muito populosas, já foram descritos aproximadamente 30 subtipos de células amácrinas, levando-se em conta, sobretudo, diferenças na morfologia celular e no conteúdo de neurotransmissores (Masland, 2001; Wassle, Boycott, 1991). Um tipo de célula amácrina que tem despertado interesse são as amácrinas colinérgicas, também conhecidas como "starburst". Três tipos de amácrinas colinérgicas foram descritos na retina de pintos adultos. O corpo celular do tipo 1 é encontrado na camada nuclear interna e seus dendritos são monoestratificados nas bordas das sublâminas 1 e 2 da camada plexiforme interna. $O$ corpo celular do tipo 2 é deslocado para a camada de células ganglionares e seus dendritos arborizam nas bordas das sublâminas 3 e 4 . Os pericários desses dois tipos de amácrinas colinérgicas são arranjados simetricamente ao longo da retina como um espelho. $O$ tipo 3 tem o corpo celular profundo na camada de células nucleares e não é descrito em mamíferos (Prada et al., 1999).

Além dos neurônios, dois tipos de células da macroglia podem ser encontrados na retina, astrócitos e células de Müller. Enquanto os astrócitos se localizam na camada ganglionar, as células de Müller atravessam a retina da membrana limitante interna até a membrana limitante externa, contribuindo para a manutenção estrutural da retina (Figura 2). As células de Müller promovem o tamponamento de íons $\mathrm{K}^{+}$provenientes da atividade neuronal e são responsáveis pela remoção e metabolização de neuromediadores do espaço extracelular (Thoreson, Witkovsky, 1999).

A comunicação intercelular e sua modulação são fundamentais para 0 processamento neuronal de modo geral, e da informação visual em particular. A despeito de hipóteses mais recentes sobre a atuação do óxido nítrico, que é um gás difusível, no meio intercelular (Cudeiro, Rivadulla, 1999), a comunicação neuronal 
classicamente é descrita como resultado da função de sinapses químicas e elétricas. Enquanto aspectos específicos das sinapses químicas na retina têm sido amplamente estudados, aplicando-se várias metodologias, o estudo das sinapses elétricas, no entanto, tem recebido menos atenção.

Na retina adulta de mamíferos, o acoplamento celular é bem difundido e muito importante na composição de diversos circuitos neurais (Vaney, 2002). Estudos com camundongos demonstraram que a Cx36 é expressa tanto no encéfalo quanto na retina, sendo que, na retina, anticorpos dirigidos contra essa Cx marcam processos de neurônios localizados tanto na camada plexiforme externa (OPL) como na camada plexiforme interna (IPL) (Dang et al., 2004). Além disso, camundongos KO para Cx36 têm problemas sérios de visão, o que mostra que essa Cx é fundamental para a sinalização visual. Deans et al., em 2002, demonstrou que sinais provenientes de bastonetes de camundongos KO para Cx36 não atingem as células ganglionares, sugerindo uma ausência completa de transferência de informação a partir de células amácrinas All para células bipolares.

Sabe-se que a Cx43, pelo menos no SNC, está presente em células da glia, principalmente em astrócitos, e no endotélio vascular, atuando na modulação de respostas frente a lesões. $\mathrm{O}$ acoplamento de astrócitos pela $\mathrm{C} \times 43$ forma um sincício glial (Naus et al., 1991; Rouach et al., 2002) que, sob condições fisiológicas normais, atua no tamponamento espacial de íons e moléculas sinalizadoras na manutenção da homeostase (Nagy and Rash, 2000; Zahs et al., 2003). Estudos mostraram que a Cx43 está envolvida com as primeiras respostas celulares à lesão, embora o papel exato permaneça controverso. Muitos relataram que a comunicação celular por canais de Cx43 está associada à propagação de sinais da morte celular (Frantseva et al., 2002; Lin et al., 1998; Rawanduzy et al., 1997), enquanto outros demonstraram efeitos neuroprotetores desta $\mathrm{Cx}$ espalhando moléculas que em altas concentrações podem ser citotóxicas (Naus et al., 2001; Nakase, Naus, 2004).

\subsection{Acoplamento celular na neurodegeneração}

Além de processos relacionados com o desenvolvimento e função visual, a regulação do acoplamento celular tem sido descrita em processos neurodegenerativos. No SN, a presença de JCs é bem caracterizada entre células da glia, constituindo uma via de distribuição de metabólitos e sinalização por 
segundos mensageiros. A propagação de ondas de $\mathrm{Ca}^{2+}$ através de JCs de astrócitos em resposta à aplicação de glutamato ou estímulo mecânico foi observada tanto em cultura como em cortes de hipotálamo (Charles, 1998).

O papel do acoplamento celular em processos apoptóticos e neurodegenerativos permanece controverso. O bloqueio de JCs por agentes farmacológicos em cultura de astrócitos aumentou a vulnerabilidade neuronal ao glutamato (Ozog et al., 2002). Em estudos de lesões no hipocampo, o bloqueio de JCs também aumentou o dano neuronal (Blanc et al., 1998). Experimentos com camundongos $\mathrm{KO}$ para $\mathrm{Cx43}$, que tiveram oclusão da artéria cerebral média, mostraram um aumento significativo da área afetada em relação ao animal selvagem (Nakase et al., 2003). Estudos sobre isquemia na retina mostraram que o bloqueio farmacológico transiente da Cx43 por peptídeo mimético diminui a morte de células ganglionares (Danesh-Meyer et al., 2012). Explantes de retinas lesadas por laser foram submetidas a tratamento com bloqueadores de JCs, resultando em um aumento significativo da morte celular secundária. Comparando a incidência de células em apoptose marcadas por TUNEL (terminal deoxynucleotidyl transferasemediated d-UTP nick end-labeling) entre animais selvagens e KO para Cx36, foi observado aumento significativo de células TUNEL-positivas nas retinas dos ratos KO. (Striedinger et al., 2005).

Por outro lado, estudos sobre a isquemia global perinatal revelaram aumento do acoplamento celular com íntima associação ao aumento da expressão de caspase-3 em slice de hipocampo. Após tratamento com CBX (carbenoxolone, bloqueador farmacológico de amplo espectro) antes, durante ou 60 minutos após a isquemia, ocorreu diminuição da apoptose e consequentemente, do espalhamento da morte neuronal secundária (de Pina-Benabou et al., 2005). Estudos em modelo de epilepsia mostraram que o CBX diminui a atividade epiléptica assim como a amplitude e frequência das ondas elétricas no eletroencefalograma (EEG). Esses resultados sugerem que a diminuição do acoplamento celular pode contribuir para a prevenção e amenização da epilepsia (Bostanci, Bagirici, 2007). O bloqueio de hemicanais de JCs por ácido glicirretínico suprimiu significativamente a perda neuronal na medula espinhal em modelo de esclerose lateral amiotrófica. Isso se deu pela diminuição da liberação de glutamato da microglia. Além disso, observouse menor perda de memória em modelo de Alzheimer (Takeuchi et al., 2011). 
A reação de TUNEL é amplamente utilizada como um método de identificação e, em alguns casos, de quantificação de células apoptóticas. Nesse ensaio, a incorporação específica de indicadores nos terminais de nucleotídeos do DNA fragmentado proporciona a identificação de células que apresentam tal fenótipo (Ben-Sasson et al., 1995). Estes resultados sugerem que o acoplamento possui um papel neuroprotetor. Outra técnica utilizada para avaliação do espalhamento da morte celular secundária após uma injúria é a quantificação de lactato desidrogenase (LDH), enzima que catalisa a conversão de piruvato em lactato, liberado no meio de cultura. Quando essa enzima é liberada em grandes quantidades sugere diminuição da viabilidade celular. (Keilhoff, Wolf, 1993).

A questão dos canais de Cxs contribuírem ou não para a morte neuronal e nas doenças neurodegenerativas tem sido debatida há muitos anos. Entretanto, perspectivas de efeitos opostos envolvendo as Cxs estão sendo discutidas e revisadas (Giaume et al., 2007; Kirchhoff et al., 2001; Nakase, Naus, 2004; Velazquez et al., 2003). Em geral, essa dualidade é atribuída a diferenças (i) no modelo experimental (in vitro, ex vivo, e in vivo), ou protocolo utilizado para indução da morte celular, (ii) no método escolhido para alterar o acoplamento de canais de JCs (moléculas com atividade farmacológica ou animais KOs), (iii) no tipo de morte celular ou patologia investigada, e (iv) aos diferentes intervalos temporais considerados no momento do estudo (Giaume et al., 2013).

\subsection{Justificativa para o estudo}

Muitos estudos sugerem a participação do acoplamento celular no espalhamento da MCP frente a insultos e/ou em casos de doenças neurodegenerativas. Geralmente são utilizados modelos que mimetizam doenças, como Alzheimer ou Parkinson, que acabam generalizando o dano neural, dificultando a delimitação da injúria e das células saudáveis. Durante nosso doutoramento, desenvolvemos um modelo de lesão focal da retina que se destaca por permitir a visualização e comparação da imunorreatividade no foco da lesão, penumbra, áreas adjacentes e regiões controles em um mesmo corte histológico. Este modelo gera gradiente de concentração de células em apoptose no foco da lesão, para células saudáveis na periferia da lesão. Desta forma, o modelo mimetiza uma situação de trauma mecânico localizado na retina ou no SN. Explantes de retina 
possibilitam também a manipulação do acoplamento por diversas moléculas, aumentando a quantidade de informações que possam auxiliar no desenvolvimento de novas terapias celulares.

A retina de pintos é um excelente modelo experimental para o estudo do SN. Esta espécie é adaptada para a visão diurna apresentando portanto similaridades com o sistema visual humano, tornando assim este estudo de grande valia na comparação entre aves e mamíferos. Além disso, o tamanho avantajado do olho desses animais e sua acessibilidade facilitam 0 estudo de processos neurodegenerativos e mecanismos compensatórios de reparo. 


\section{OBJETIVOS}

\subsection{Gerais}

Visto que estudos sobre o papel do acoplamento celular na neurodegeneração ainda são muito controversos com relação ao papel pró- ou antiapoptótico, temos interesse em participar dos esforços em compreender as consequências de lesões neuronais e espalhamento de morte celular secundária. Nosso objetivo é avaliar o possível envolvimento das JCs, utilizando a retina como um modelo de estudo do SNC

\subsection{Específicos}

1. Analisar a expressão das $C \times 36$ e $C x 43$ na retina de pintos submetidos à lesão mecânica;

2. Descrever o padrão de distribuição de células em apoptose que expressam as Cxs estudadas;

2. Medir a viabilidade celular de explantes de retinas lesadas com bloqueadores e abridores de JCs como carbenoxolone (CBX), quinina e trimetilamina (TMA);

3. Avaliar a expressão gênica de caspases 3,8 e 9 em retinas tratadas com bloqueadores de JCs;

4. Avaliar as mudanças no padrão de distribuição de células apoptóticas em explantes de retinas lesadas tratadas com bloqueadores de JCs;

5. Avaliar as mudanças no padrão de distribuição de células apoptóticas em retinas lesadas em olhos injetados com bloqueadores de JCs. 


\section{MATERIAIS E MÉTODOS}

Utilizamos diferentes metodologias para determinar a expressão de Cxs durante a degeneração por trauma mecânico da retina de pintos e o papel do acoplamento celular neste modelo de lesão aguda.

\subsection{Padronização do modelo de lesão retiniana}

Utilizamos pintos (Gallus gallus) com 10 a 20 dias de vida. Após a aplicação de anestésico e relaxante muscular (quetamina e xilazina, 1:1), as lesões foram feitas nos olhos dos animais por meio de uma agulha de insulina. Durante este procedimento, a agulha atravessou: córnea, humor vítreo, retina, epitélio pigmentado e esclera. Os animais foram sacrificados nos intervalos de 6 horas, 1, 3 e 7 dias póslesão para caracterização do espalhamento da apoptose e após 1, 3 e 7 dias para avaliação da expressão gênica e níveis proteicos. Os períodos foram escolhidos com base em estudos de lesão no SNC. Em 2002, Alzheimer publicou que entre 1 e 3 dias após a lesão temos um período agudo, entre 4 e 8 dias temos um período subagudo e então, vem a fase de consolidação que já não nos interessa. Após os diferentes períodos de lesão, os animais foram sacrificados com overdose de quetamina e xilazina, conforme as regras da Comissão de Ética em Experimentação Animal do Instituto de Ciências Biomédicas da Universidade de São Paulo, e seus olhos foram retirados. As retinas foram dissecadas para diferentes metodologias. $\mathrm{Na}$ figura 7, pode-se observar o olho aberto contendo lesões na retina, e uma retina dissecada para experimentos funcionais. Essa figura foi publicada no artigo " $A$ new and reliable guide for studies of neuronal loss based on focal lesions and combinations of in vivo and in vitro approaches." publicado na PloS one 8:e60486 em 2013, de autoria de Paschon V, Higa GS, Walter LT, de Sousa E, Zuzarte FC, Weber VR, Resende RR, Kihara AH. 
Figura 7- Dissecção da retina para experimentos funcionais.

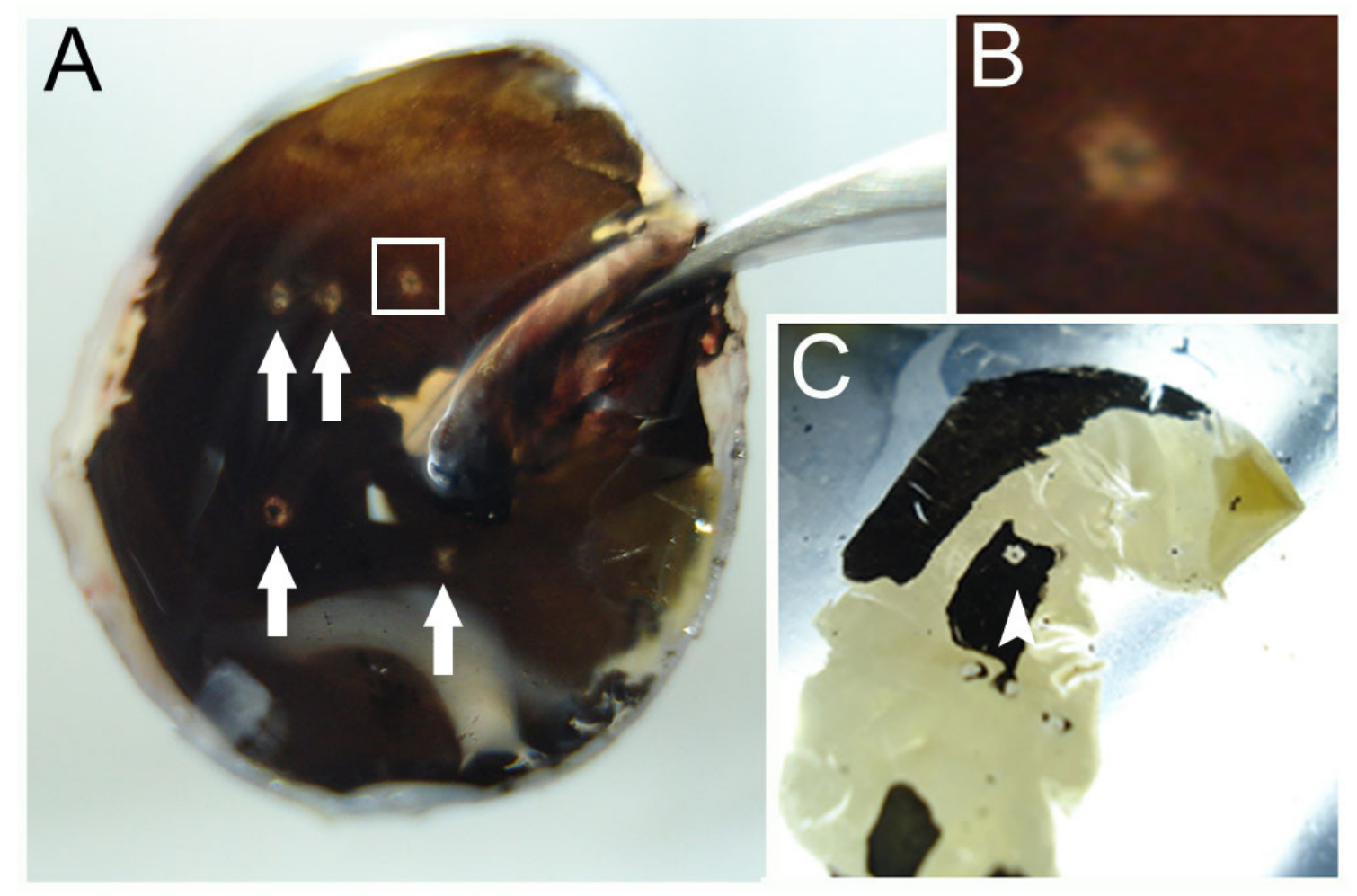

(A) Fundo do olho contendo lesões pontuais na retina de pinto. (B) Imagem com maior aumento de uma lesão feita com agulha de insulina. (C) Retina dissecada para experimentos funcionais onde podemos observar lesões e acúmulo de epitélio pigmentado nas regiões de lesão.

Fonte: Paschon et al., 2013.

\subsection{Quantificação da expressão gênica de Cxs por PCR em tempo real}

As retinas dissecadas foram homogeneizadas em $1 \mathrm{ml}$ de TRIzol (Invitrogen, Carlsbad, CA, USA) e o RNA total foi extraído de acordo com instruções do fabricante e previamente descrito (Kihara et al., 2005). Após dois passos de extração com clorofórmio, o RNA foi precipitado com isopropanol e o pellet foi lavado duas vezes com etanol $70 \%$. Após secagem, o RNA foi ressuspendido em água tratada com DEPC e a concentração foi mensurada por espectofotometria a $260 \mathrm{~nm}$. O DNA residual foi removido utilizando DNAse I (Amersham, Piscataway, NJ, USA) de acordo com protocolo do fabricante. A análise da expressão gênica foi realizada no Rotor Gene 6000 (CorbettRobotics Inc., San Francisco, CA) com primers específicos para Cx36 (sense, 5'-TTGGTGTTCATGTTTGCTGTCA-3'; anti-sense, 5'CCAGCCCAAGTGGTTCAGTT-3')

Cx43 (sense, 
CTGAGTGCCATCTACACCTGTGA-3'; anti-sense; 5'-TTGGACGGGACAGGAAACA3') de pintinhos. O gene GAPDH, também específico para pintinhos, foi utilizado como controle interno (sense, 5'- GGTGCTAAGCGTGTTATCATCTCA-3'; antisense, 5'-CATGGTTGACACCCATCACAA-3'). Para cada $20 \mu \mathrm{l}$ de reação de transcrição reversa, foram misturados $4 \mu \mathrm{g}$ de RNA total com $1 \mu \mathrm{l}$ de primer oligodT

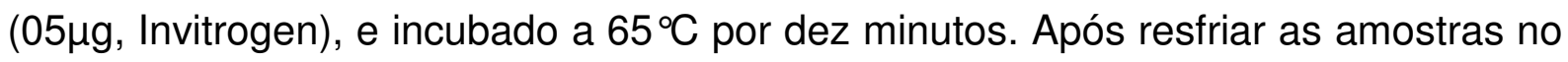
gelo, a solução foi misturada com $4 \mu$ l de tampão firststrand $5 x, 2 \mu$ DTT 0,1 M, $1 \mu$ l de dATP, dTTP, dGTP e dUTP (cada um em 10mM) e $1 \mu$ de transcriptase reversa SuperScript III (200 U; Invitrogen) e incubado por 60 minutos a $50^{\circ} \mathrm{C}$. A reação foi inativada aquecendo as amostras a $70^{\circ} \mathrm{C}$ por 15 minutos. Utilizamos o sistema SYBR Green com 50\% do volume total da amostra (ex: $30 \mu l$ de amostra $+15 \mu \mathrm{l}$ de SYBR Green). Todos os ensaios de PCR foram realizados da seguinte maneira: Após ativação inicial em $50^{\circ} \mathrm{C}$ por dois minutos e $95^{\circ} \mathrm{C}$ por dez segundos e $60^{\circ} \mathrm{C}$ por um minuto. As curvas de dissociação foram obtidas por aquecimento das amostras de $60^{\circ} \mathrm{C}$ a $95^{\circ} \mathrm{C}$, a fim de avaliar a especificidade dos primers.

A quantificação relativa foi avaliada pelo método comparativo CT, como previamente descrito (Medhurst et al., 2000). No cálculo, o CT médio do grupo controle é utilizado como uma constante para subtrair de todas as outras médias empíricas. Utilizamos um $\mathrm{N}$ de 8 animais para os experimentos de PCR em tempo real.

\subsection{Quantificação dos níveis proteicos por Western Blot}

Retinas de pintos com diferentes idades pós-lesão (1, 3 e 7 dias) foram homogeneizadas em solução Tris-HCL $25 \mu \mathrm{M}$ contendo inibidores de protease. Retinas contralaterais de cada animal foram usadas como controle. Utilizamos um $\mathrm{N}=6$ em cada grupo. As amostras foram centrifugadas a $10.000 \mathrm{rpm}$ por $10 \mathrm{~min}$, e o sobrenadante foi coletado para dosagem pelo método de breadford (Biorad RC DCTM Protein Assay Kit II 500-0122) seguindo as instruções do fabricante. As amostras foram diluídas no tampão Laemmli com DDT para realizar o western blot. $70 \mu \mathrm{g}$ de proteína de cada amostra e mais $7 \mu \mathrm{l}$ de marcador de peso molecular (BioRad, Precision Plus Protein Standards, Cat\# 161-0375) foram aplicados em gel de separação de poliacrilamida (Bio-Rad, 40\% Acrylamide/Bis Solution, Cat\# 161-0148) a $12 \%$ com gel do pente a $4 \%$, inicialmente a $30 \mathrm{~V}$ e aumentando gradativamente até 
110V em tampão de corrida 1X. As proteínas foram separadas por eletroforese e transferidas para membrana de nitrocelulose (Bio-Rad, Nitrocellulose Membrane, Cat\# 9004-70-0), que foram coradas com Ponceau (0,1\%). A transferência foi feita com $15 \mathrm{~V}$ por $1 \mathrm{~h}$ 20min na célula de transferência semidry (Bio-Rad, Transblot SD Semidry Transfer Cell). As membranas foram bloqueadas em uma solução de albumina 3\% em PBS $\left(\mathrm{Na}_{2} \mathrm{HPO}_{4}\right.$ 0,08M, NaH $\mathrm{PO}_{4} 20 \mu \mathrm{M}, \mathrm{NaCl} 50 \mu \mathrm{M}$ e 0,1\% de Tween 20) antes de serem incubadas com anticorpo primário anti-Cx36 feito em coelho (Invitrogen, 989584A) e anti-Cx43 feito em coelho (Invitrogen, 844180ㄹ) por 12-24 horas $\left(4^{\circ} \mathrm{C}\right)$ em PBS contendo leite $5 \%$. Após lavagens em TTBS ( $\mathrm{NaCl} 0,5 \mathrm{M}$, Tris- $\mathrm{HCl} 50 \mu \mathrm{M}$, Tween 20 0,1\%), as membranas foram incubadas com anticorpo secundário marcado com peroxidase em TTBS por 2 horas à temperatura ambiente. O sinal das bandas foi detectado utilizando o ECL (Amersham ECL PlusTM Western Blotting Detection System RPN2132, GE Healthcare) e filme (Kodak). Como controle interno utilizamos o gene GAPDH. As imagens obtidas foram analisadas com o programa ImageJ.

\subsection{Caracterização do padrão de distribuição proteica por imuno-histoquímica}

Os animais foram anestesiados e perfundidos com solução salina $(0,9 \%)$ e paraformaldeído (PFA) 4\%. Os olhos foram pós-fixados em PFA 1\% (para experimentos com anticorpos para Cxs) e PFA 4\% (para experimento de caracterização da gliose reativa) em tampão fosfato $0,1 \mathrm{M}, \mathrm{pH} 7,4$ (PB) por 30-60 minutos e crioprotegidos em sacarose $30 \%$ em PB por 30-60minutos. Utilizamos um $\mathrm{N}=3$ em cada grupo. Secções transversais $(12 \mu \mathrm{m})$ da retina foram obtidas em criostato e colhidas diretamente em lâminas de vidro gelatinizadas.

Para determinar o padrão de distribuição de Cx36 e Cx43 nos diferentes períodos pós-lesão (1, 3 e 7 dias) utilizamos os anticorpos primários: anti-Cx36 feito em coelho (Invitrogen, 989584A) e anti-Cx43 feito em coelho (Invitrogen, 844180A); na concentração de 1:100. Os anticorpos primários foram diluídos em 0,5\% Triton X100 em PB e a incubação foi feita por 12-24 horas a temperatura ambiente. A seguir, os cortes foram incubados com anticorpo secundário conjugado com Alexa488 anticoelho feito em jumento (Invitrogen, A21206) diluído 1:500 em 0,5\% Triton X-100 em PB. Finalmente, os cortes foram contracorados com DAPI 1:60.000 diluido em 0,5\% Triton X-100 em PB. 
Para caracterizar a gliose reativa após 7 dias de lesão utilizamos o anticorpo primário contra GFAP (proteína fibrilar glial, Sigma G3893) na concentração de 1:200 diluído em 0,3\% Triton X-100 em PB, o anticorpo secundário utilizado foi o ALEXA-350 anti-camundongo feito em cabra (Invitrogen, A21140) na concentração de 1:500 diluído em 0,3\% Triton X-100 em PB. E as camadas das retinas foram contracoradas com iodeto de propídio (PI) nesse caso 1:60.000 diluido em 0,3\% Triton X-100 em PB.

Controles para especificidade de marcação incluirão: (1) omissão dos anticorpos primários; (2) pré-adsorção com o peptídeo imunogênico usado para a produção do anticorpo. A marcação foi considerada específica se abolida nessas condições. Em nosso laboratório alguns dos anticorpos contra Cxs já foram testados em retinas de camundongo KO (Kihara et al., 2006).

\subsection{Avaliação do espalhamento da apoptose por TUNEL}

Lâminas fixadas em PFA 4\% foram lavadas 2 vezes de 10min em PB 0,05M $(\mathrm{pH} 7,4)$ no agitador orbital, então foram incubadas em uma solução permeabilizante contendo $0,1 \%$ de Triton X-100 e 0,1\% de citrato de sódio em PB 0,05M por dois min no gelo. As lâminas foram lavadas 2 vezes de $5 \mathrm{~min}$ em PB $0,1 \mathrm{M}$ e incubado por 60 min a $37^{\circ} \mathrm{C}$ com uma mistura do kit para TUNEL (Roche Molecular Biochemicals, Mannheim, Germany) contendo a enzima transferase (TdT) e os nucleotídeos marcados com fluoresceína na proporção de 1:5. Em seguida, o material foi lavado 2 vezes de $5 \mathrm{~min}$ em PB $0,1 \mathrm{M}$. As lâminas reagidas foram cobertas com meio de montagem (glicerol) e lamínulas seguido de uma fina camada de esmalte nas bordas para fixar. Finalmente, o material foi analisado em microscópio de fluorescência equipado com filtro para fluoresceína.

\subsection{Experimentos de dupla e tripla marcação com TUNEL}

Experimentos de dupla-marcação foram realizados para determinar o padrão de distribuição e proximidade das células que expressam Cx36 e TUNEL. Para isso, realizamos imunofluorescência simples da Cx36 como descrito acima, seguida do ensaio de TUNEL, também descrito acima. 
Para determinar se a modulação de expressão proteica de Cx36 ocorreu em subgrupos específicos de neurônios, alguns estudos de dupla marcação também foram realizados. Primeiramente incubamos os anticorpos primários e secundários descritos acima para $\mathrm{Cx36}$ e somente depois utilizamos anti-Choline Acetyltransferase (anti-ChAT, Millipore, AB144P) diluído 1:50 em PB com 0,3\% Triton X-100 por 12-24 horas em temperatura ambiente. Como anticorpo secundário usamos o ALEXA-546 anti-cabra feito em jumento (Invitrogen, A21140) na concentração de 1:500 diluído em 0,3\% Triton X-100 em PB. Por fim, os cortes foram contracorados com DAPI 1:60.000 diluido em 0,3\% Triton X-100 em PB.

\subsection{Ensaio de liberação de lactato desidrogenase (LDH) e avaliação da expressão gênica de caspases}

Explantes de retinas lesadas com 12-24 horas de sobrevida foram incubadas com meio de cultura (BME + glutamina + soro fetal bovino SFB) contendo PBS, bloqueadores de JCs ou abridores de JCs por 4 horas, nas concentrações de $50 \mu \mathrm{M}$ ou $100 \mu \mathrm{M}$. Os bloqueadores de JCs utilizados foram o carbenoxolone (CBX, bloqueador inespecífico, Sigma, C-4790), a quinina (bloqueador específico de Cx36 e Cx50, Sigma, Q-1250) e a combinação dos dois bloqueadores (CBX + quinina). $O$ abridor de JCs utilizado neste estudo foi O TMA (trimetilamina, Sigma, T7,276-1). Amostras de meio de cultura foram coletadas após 1, 2 e 4 horas de incubação para quantificação colorimétrica do LDH liberado, como medida de viabilidade celular, por meio de kit de lactato desidrogenase (Labtest, São Paulo - SP, Brasil). Os resultados foram obtidos através da medida da absorbância em 500nm por meio de um biofotômetro (Eppendorf, Santo André - SP, Brasil).

Após o experimento de $\mathrm{LDH}$, as retinas incubadas com CBX, quinina, CBX+quinina e PBS (apenas na concentração de 100 $\mu \mathrm{M}$ ) foram lavadas em salina e processadas para experimento de PCR em tempo real para avaliação da expressão gênica de caspases-3, 8 e 9. O protocolo utilizado foi o mesmo descrio acima para Cxs. Desenhamos também primers específicos para caspase-3 (sense, 5'CCGGACTGTCATCTCGTTCA-3'; anti-sense,

5

TTTATATCCCAGCTTCATAAAAACTTCTC-3'), caspase-8 (sense, 5'TGGGCAGGAAGTACCTATCCA-3'; anti-sense, 5'-CCAGCAAGTGATTGGCAATTT3'), e caspase-9 (sense, 5'-ACCTTGGACAGCGTACTGGAA-3'; anti-sense, 5'- 
TGACACCCGAAGTAGCTTGGT-3') de pintinhos. Como controles internos, também utilizamos o GAPDH descrito acima.

\subsection{Incubação de explantes de retinas lesadas com bloqueadores de JCs para quantificação do espalhamento da morte celular secundária}

Explantes de retinas lesadas com 24 horas de sobrevida foram incubadas com meio de cultura (BME + glutamina + soro fetal bovino SFB) contendo PBS, ou bloqueadores de JCs (CBX, quinina ou CBX + quinina) por 4 horas, na concentração de $100 \mu \mathrm{M}$. Depois deste período de incubação as retinas foram fixadas em PFA 4\% e congeladas para obtenção de cortes em criostato para ensaio de TUNEL com o objetivo de caracterizar o padrão de distribuição e espalhamento de células TUNELpositivas no tratamento com bloqueadores de JCs.

\subsection{Injeção de bloqueadores de JCs in vivo para quantificação do espalhamento da morte celular secundária}

Pintos com aproximadamente 10 a 20 dias tiveram seus olhos lesados com agulha de insulina e ao mesmo tempo foi feita uma injeção intraocular de bloqueadores de JCs (CBX, quinina ou CBX + quinina) na concentração de 500 $\mu \mathrm{M}$. Após 24 horas, os animais foram sacrificados e as retinas foram fixadas com PFA $4 \%$ e congeladas para obtenção de cortes em criostato para ensaio de TUNEL com o objetivo de caracterizar o padrão de distribuição e espalhamento de células TUNEL-positivas no tratamento com bloqueadores de JCs.

\subsection{Análise dos resultados}

Dados provenientes de análises quantitativas (por exemplo, PCR em tempo real e contagem de células) foram submetidos à análise de variância (ANOVA) seguida de teste de Tukey, com valor de significância igual a 5\%. Além disso, resultados foram considerados apenas quando reprodutíveis em pelo menos três experimentos independentes.

A análise das imagens foi feita pelo software Image-Pro Plus (Media Cybernetics, Bethesda, MD, USA). Após a separação dos canais (RGB) das 
imagens, realizamos dois tipos de analises: i) contagem do número de núcleos TUNEL-positivos após padronização apropriada do tamanho e brilho. Após a contagem automática de núcleos pelo software, artefatos e background puderam ser identificados e descartados. ii) Análises "bitmap" $x-y$ geraram dados numéricos correspondentes a quantidade e intensidade de pixels. Essa análise gerou uma matriz com valores que foi exportada para o Excel (Microsoft, Redmond, WA, USA). Esses dados também foram submetidos à análise de variância (ANOVA) seguida de teste de Tukey, com valor de significância igual a 5\%.

Os painéis contendo imagens e gráficos apresentados nos resultados foram preparados utilizando o Adobe Photoshop CS2 (Adobe Systems Inc., San Jose, CA, USA). 


\section{RESULTADOS}

\subsection{Caracterização da expressão gênica e níveis proteicos de Cxs na degeneração da retina por trauma mecânico}

A expressão gênica e os níveis proteicos de Cxs são especificamente regulados durante a degeneração da retina. Detectamos transcritos de Cx36 e Cx43, utilizando PCR em tempo real, no modelo de neurodegeneração por lesão em diferentes períodos pós-lesão (1, 3 e 7 dias). A especificidade dos primers para Cx36 e Cx43 foi testada em estudos anteriores (Kihara et al., 2008, Kihara et al., 2009) e por análise das curvas de dissociação (dados não mostrados). Observamos perfis diferenciados de expressão para a C×36 e Cx43 durante a degeneração da retina induzida por trauma mecânico. A expressão gênica da $C \times 36$ não foi regulada significativamente em nenhum período analisado (Fig. 10). Por outro lado (Figura 10B), observamos que a Cx43 teve os níveis de RNAm aumentados após 1 dia, ao fim de 3 dias voltaram ao estado normal, e aumentaram significativamente após 7 dias $(182 \%, P<0,05)$. Analisamos também os níveis proteicos da Cx36 e Cx43 por Western Blot (Fig. 10C). Os níveis proteicos de Cx36 diminuíram significativamente após $3(223 \%, P<0.05)$ e $7(234 \%, P<0.05)$ dias de lesão (Fig. 10 d). Por outro lado, observamos aumento significativo da $\mathrm{Cx} 43(+27 \%, \mathrm{P}<0.05)$ após 7 dias (Fig. 10E). Os níveis de beta-actina foram avaliados como controle interno (Fig. 10F). 
Figura 8- Expressão gênica e níveis proteicos da Cx36 e da Cx43 após neurodegeneração da retina induzida por trauma mecânico.
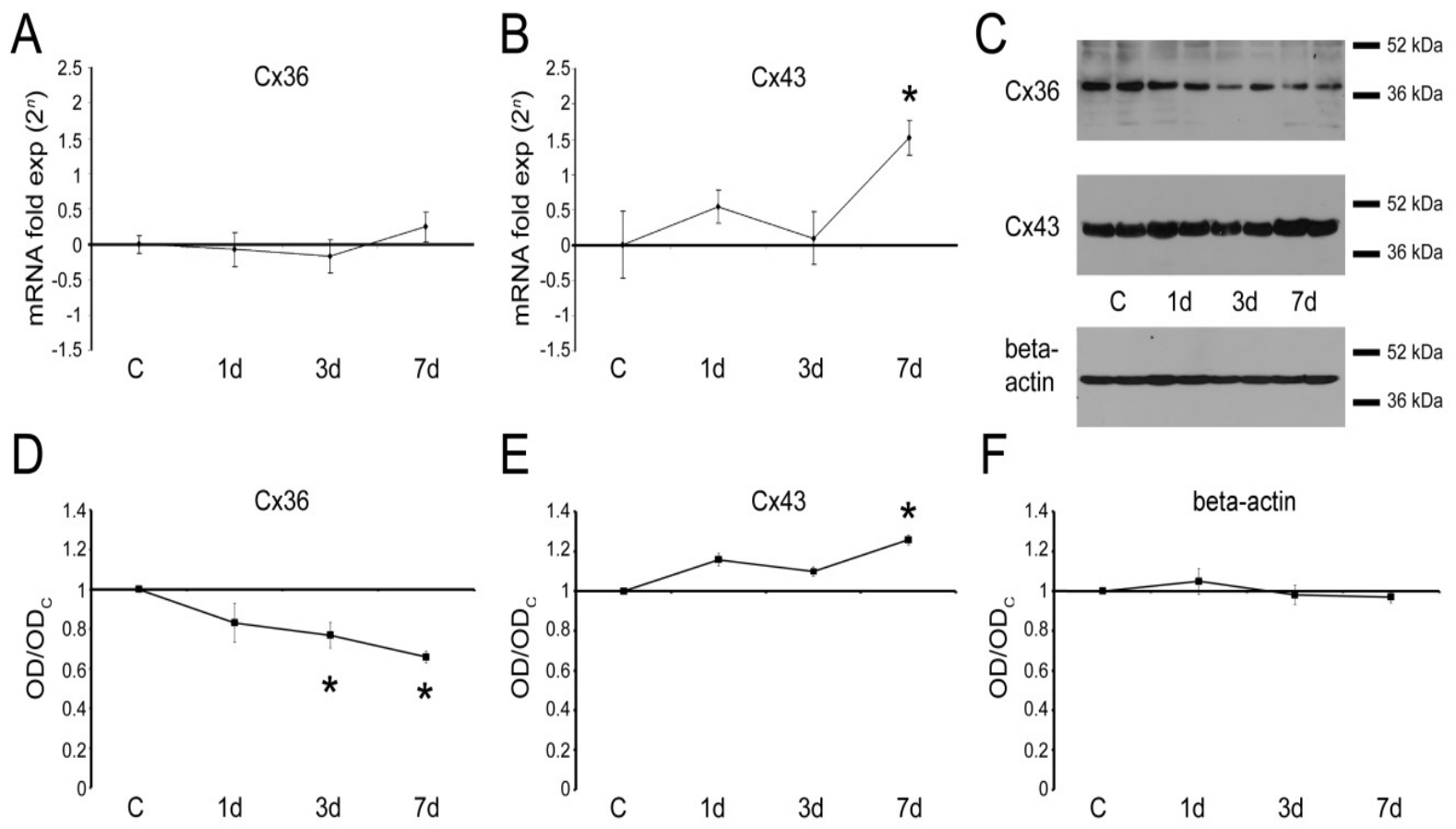

$\mathrm{F}$

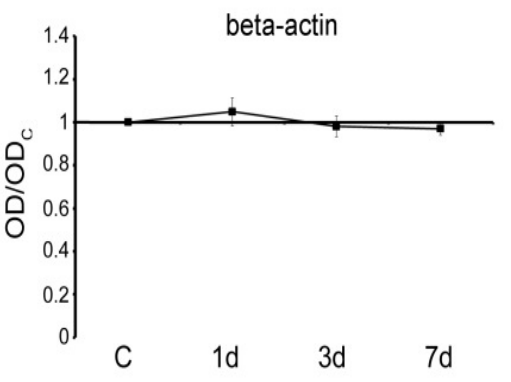

Analisamos a expressão gênica das Cx36 e Cx43 na retina por PCR em tempo real, utilizando primers desenhados contra Cx36 e Cx43 de pinto. Os resultados foram normalizados pela média do grupo controle, e foram apresentados como expressão exponencial (2n). (A) Observamos que os níveis de expressão gênica da Cx36 não foram alterados significativamente após 1, 3 e 7 dias pós-lesão. (B) Os níveis de RNAm da Cx43 não alteraram estatisticamente após 1 e 3 dias. No entanto, observamos regulação positiva significativa após 7 dias de lesão $(182 \%, P, 0,05)$. Os níveis de proteína foram analisados por Western blot. A densidade óptica (OD) das bandas para cada proteína de retinas controle foi utilizada para normalizar a densidade óptica de retinas lesadas em três experimentos independentes realizados em duplicatas. (C) Bandas de Cx36 e Cx43 na retina controle e lesadas utilizando anticorpos específicos. Beta-actina (42 kDa) foi usada como controlo interno. (D) Observamos diminuição dos níveis de proteína da Cx36 na retina após $3(223 \%, P<0,05)$ e $7(234 \%, P<0,05)$ dias pós a lesão. (E) Por outro lado, os níveis de proteína da Cx43 aumentaram significativamente após 7 dias $(27 \%, P<0,05)$. Barras representam erros padrão da média. ${ }^{*} \mathrm{P}<0,05$ após uma via seguida de comparações de pares de Newman-Keuls.

Fonte: Paschon et al., 2012. 


\subsection{Cx36 mantém padrão de distribuição constante durante a degeneração da retina}

Analisamos a distribuição da Cx36 durante a degeneração da retina causada por lesão mecânica. Retinas controles tiveram uma distribuição espacial semelhante ao padrão descrito em estudos anteriores (Kihara et al., 2009), com marcação puntiforme na camada plexiforme interna, formando linhas horizontais. Além disso, essa mesma marcação puntiforme foi observada na camada plexiforme externa (Fig. 11, A-C). Após 1 dia de lesão, um padrão de marcação inesperado foi observado na camada nuclear externa, ou seja, a ocorrência de células que expressam Cx36 foram observadas próximas do local da lesão (Fig. 11, D-F). Depois de 3 e 7 dias de lesão (Fig. 11, J-L), a despeito do progresso da degeneração, a marcação puntiforme de Cx36 manteve-se constante, indicando a presença desta proteína nestes momentos. 


\section{Figura 9- Imunofluorescência de Cx36 em secções transversais da retina de pinto após lesões mecânicas.}
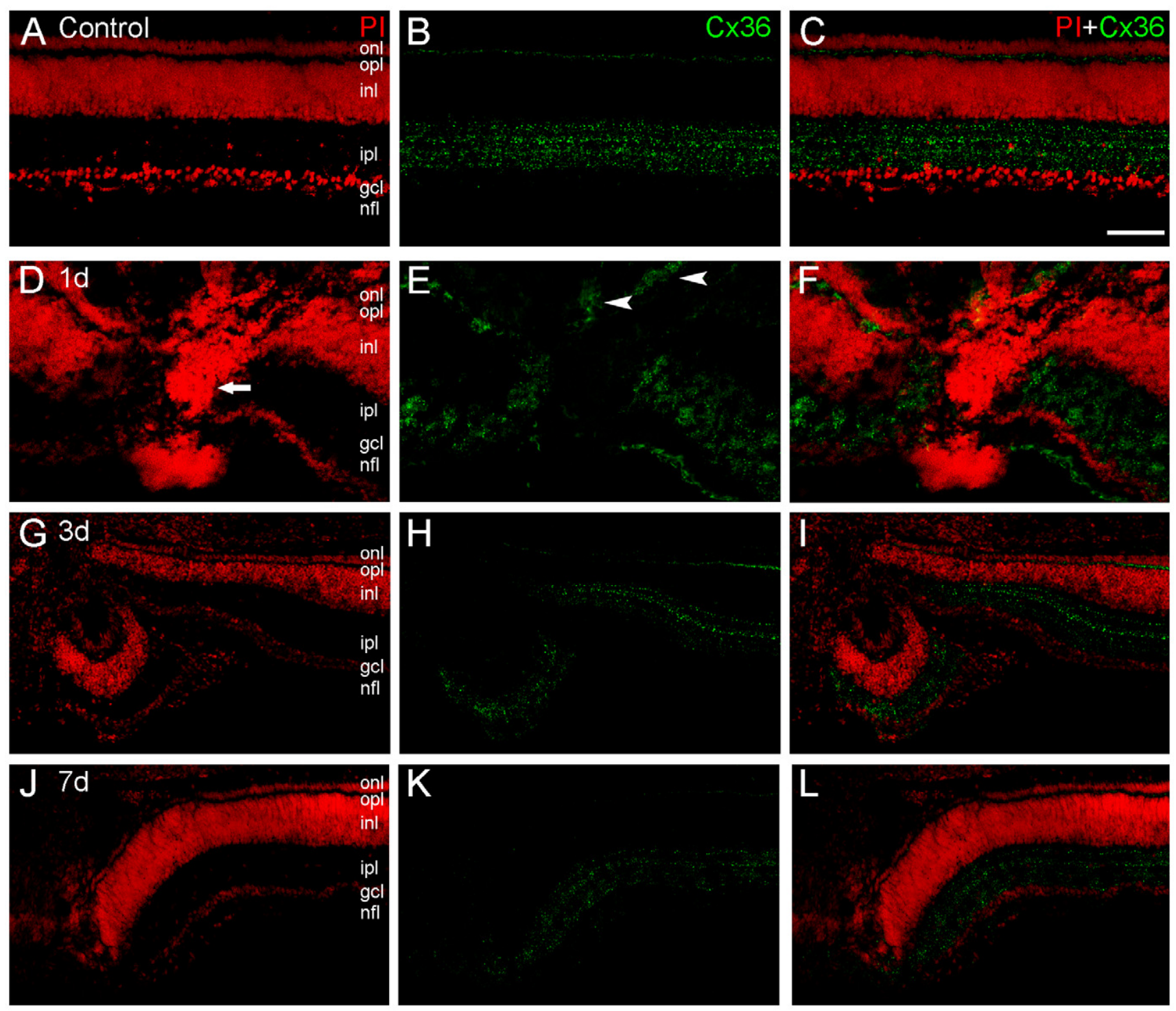

Foi possível determinar a distribuição espacial da Cx36 (verde) em retinas contracoradas com iodeto de propídio (PI, vermelho) em retinas controle (A-C) e depois de 1 - (D-F), 3 - (GI) e 7-dias (J-L) da lesão mecânica. Observamos um padrão de distribuição de Cx36 semelhante ao descrito em estudos anteriores nas retinas controles, com marcação puntiforme formando linhas horizontais na camada plexiforme interna (IPL), bem como na camada plexiforme externa (OPL). No foco da lesão foi possível observar um aumento da marcação de $\mathrm{PI}$ evidenciando núcleos de células que estão em processo de apoptose (setas). Em retinas com 1 dia de lesão, observamos um padrão de marcação inesperado na camada nuclear externa (pontas de seta), revelando que as células nesta camada expressam Cx36 e se encontram próximo da lesão. Nas retinas com 3 e 7 dias de lesão, mesmo com o processo de generação, a marcação da Cx36 permanece puntiforme, indicando a presença desta proteína nestes períodos após a lesão. Barra de escala: $60 \mu \mathrm{M}$. Fonte: Paschon et al., 2012. 


\subsection{Cx43 está presente na camada de células ganglionares durante a degeneração da retina}

Determinamos o padrão de distribuição espacial da Cx43 na retina após lesão mecânica. Retinas controles mostraram um padrão de distribuição espacial semelhante ao padrão descrito em estudos anteriores (Kihara et al., 2008), com uma clara marcação puntiforme localizada na camada de células ganglionares, além de uma fina marcação puntiforme nas camadas plexiformes interna e externa (Fig. 12, A- C). Em retinas após 1 dia de lesão, observamos um aumento da marcação de Cx43 no foco da lesão. Uma marcação puntiforme diferenciada e brilhante foi observada na camada de células ganglionares, rodeando grandes núcleos de células. Além disso, a marcação de $\mathrm{C} \times 43$ foi observada no epitélio pigmentado, como descrito em estudos prévios (Fig. 12, D-F). Após 3 dias, observamos marcação puntiforme de $\mathrm{C} \times 43$ na área de penumbra, dentro da camada de células ganglionares e também na parte interna da camada nuclear interna (Fig. 12, G-I). Em retinas após 7 dias de lesão, observamos uma marcação menos definida, mas puntiforme, no foco da lesão, com um padrão bastante desorganizado (Fig. 12, J-L). 
Figura 10- Imunofluorescência de Cx43 em secções transversais da retina de pinto após lesões mecânicas.
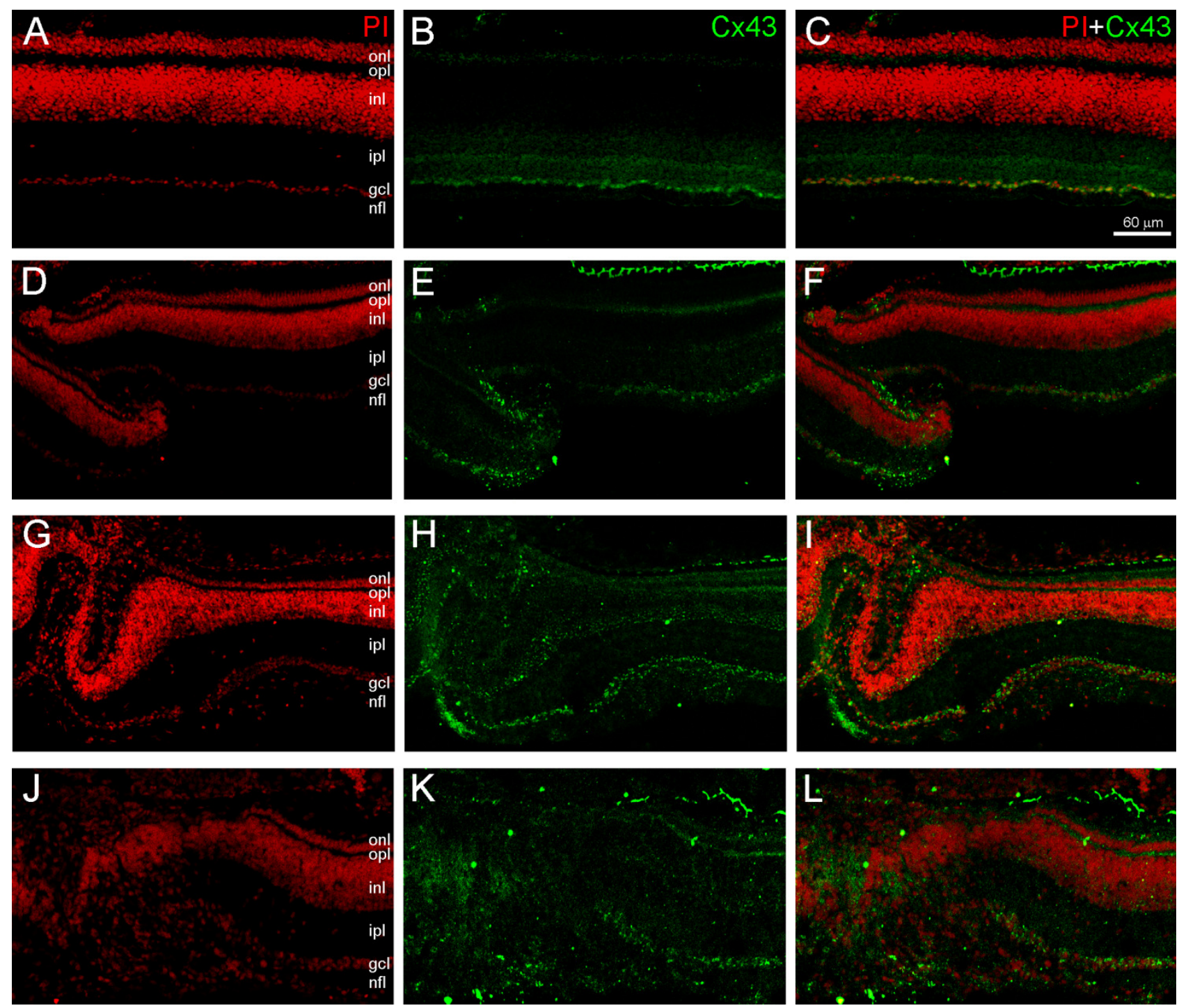

Foi possível determinar a distribuição espacial da Cx43 (verde) em retinas contracoradas com iodeto de propídio (PI, vermelho) em retinas controle (A-C) e depois de 1 - (D-F), 3 - (GI) e 7-dias $(\mathrm{J}-\mathrm{L})$ da lesão mecânica. Retinas controles mostraram um padrão de distribuição de Cx43 semelhante ao que foi descrito em estudos anteriores, com uma marcação puntiforme localizada na camada de células ganglionares (GCL), e uma fina marcação, também puntiforme, localizada na camada plexiforme interna (IPL) e na camada plexiforme externa (OPL). Em retinas com lesões de 1 dia, observou-se um aumento da marcação para Cx43 no foco da lesão. Uma marcação diferenciada e mais brilhante foi observada na camada de células ganglionares, rodeando grandes núcleos de células (setas). Notou-se que algumas marcações estão localizadas no centro da imagem na área que corresponde à GCL. Além disso, na parte superior da imagem, uma marcação de Cx43 foi descrita no epitélio pigmentado, resultado corroborado por outros estudos. Em retinas com lesões de 3 dias, a marcação puntiforme da Cx43 foi observada nas proximidades do foco da lesão, na área de penumbra, na GCL (cabeças de seta), e também na parte interna da camada nuclear interna. Em retinas com lesões de 7 dias, observou-se uma marcação puntiforme enevoada no foco da lesão, com um padrão desorganizado. Longe do foco, a imunorreatividade da Cx43 foi observada na GCL. Escala bar: $60 \mu \mathrm{M}$.

Fonte: Paschon et al., 2012. 


\subsection{Caracterização da gliose reativa no modelo de lesão após 7 dias}

Foram realizados experimentos para caracterizar a gliose reativa recorrente da lesão na retina de pintos utilizando o modelo de lesão proposto (Figura 9). Na retina controle, observamos a marcação de astrócitos na GCL e NFL e uma fraca marcação vertical de células de Muller. Com a lesão, destacou-se uma intensa marcação destes tipos celulares no foco da lesão que foi diminuindo nas áreas adjacentes. Com a análise pixel a pixel foi possível quantificar este padrão de resposta em um gráfico representando áreas a serem analisadas neste estudo. $O$ pico de reatividade refere-se ao foco da lesão, conforme a intensidade da fluorescência do GFAP diminui podemos delimitar regiões adjacentes à lesão e é possível observar até áreas controles na mesma fotomicrografia.

Esse aumento da imunorreatividade do GFAP após 7 dias ocorre concomitantemente com o aumento da expressão de Cx43 após 7 dias de lesão. Há muito se sabe que astrócitos expressam de Cx43 no SN e que em caso de lesões, ocorre proliferação glial. Provavelmente o aumento de Cx43 esteja intimamente relacionado com essa gliose reativa decorrente da lesão. 
Figura 11- Caracterização de gliose reativa decorrente da lesão.
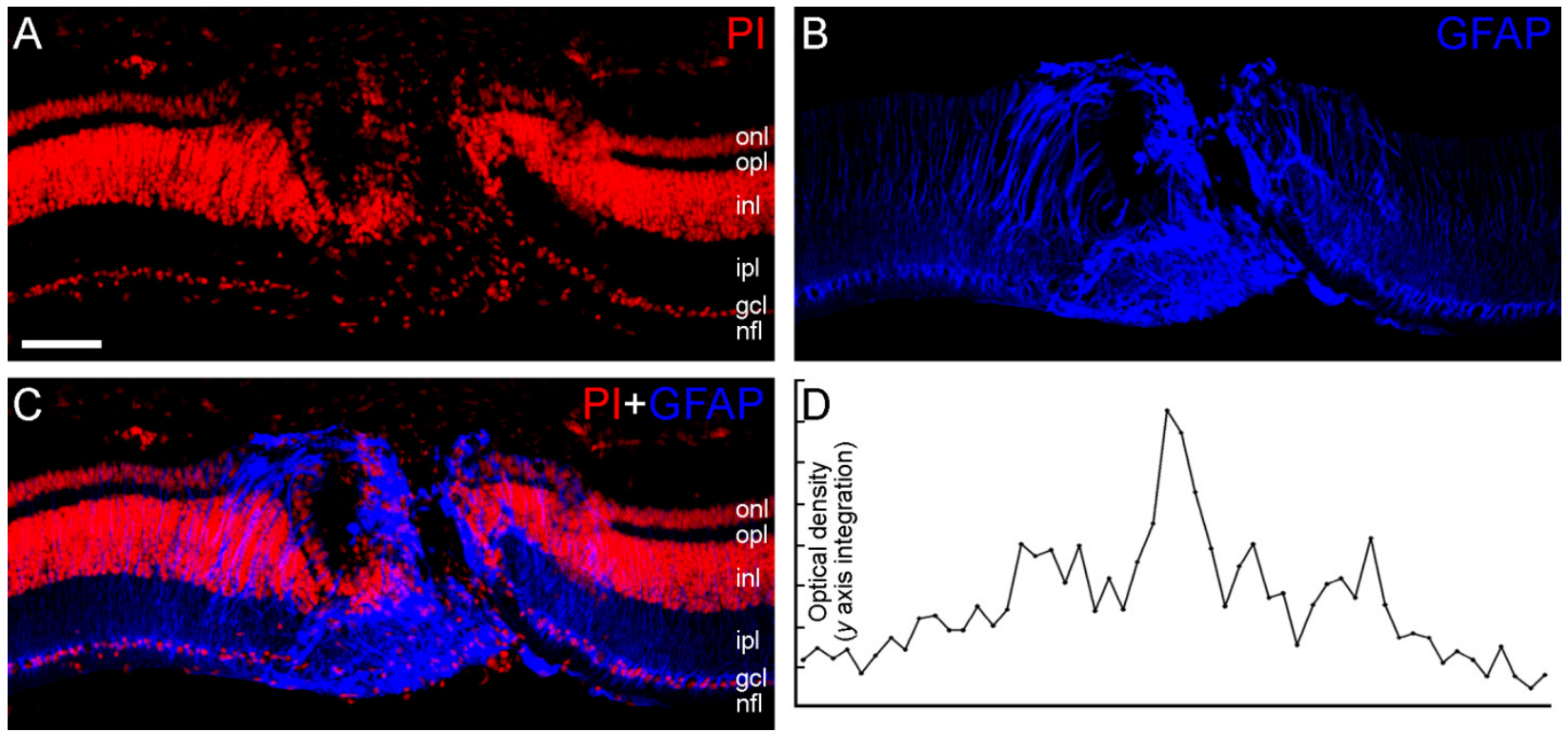

(A) Contra coloração das camadas nucleares da retina por PI. A área central interrompida corresponde ao centro da lesão. (B) Caracterização da expressão de GFAP (marcador de células de Müller na retina de pintos) no modelo de lesão. O padrão normal de expressão de GFAP é uma marcação de processos na GCL e NFL, com alguns processos verticais cruzando a IPL. (C) Sobreposição das imagens em A e B. No foco da lesão a marcação foi observada em processos verticais cruzando a INL, OPL e ONL. (D) Gráfico representando a densidade óptica da imagem mostrada em B. A análise pixel/pixel da densidade óptica foi integrada no eixo $y$, evidenciando a gliose reativa que ocorre em resposta à lesão. Barra de escala: $60 \mu \mathrm{M}$.

Fonte: Paschon et al., 2013. 


\subsection{Pico de apoptose ocorre entre 6 e 24 horas após o trauma mecânico}

Experimentos utilizando a técnica de TUNEL foram realizados para determinar a dinâmica do processo apoptótico. Detectamos núcleos apoptóticos em retinas com poucas horas de lesão (apenas 6 horas após o início do trauma mecânico) (Fig. 13, A-C), localizados principalmente no foco da lesão. Em retinas após 1 dia de lesão, observamos um pico no número de células TUNEL-positivas, localizadas principalmente no foco da lesão (Fig. 13, D-F). Estas células encontram-se distribuídas principalmente na camada nuclear interna, mas também apareceram na camada nuclear externa. Em retinas após 3 dias de lesão, observamos uma diminuição no número de células TUNEL-positivas. Estas células estavam localizadas longe do foco, na área de penumbra, evidenciando a morte celular secundária (Fig. 13, G-I). Em retinas com lesões de 7 dias, observamos pouco, ou muitas vezes nenhum, núcleo de célula TUNEL-positiva em secções transversais da retina (Fig. 13, J-L). Tomados em conjunto, estes resultados evidenciam a presença de células apoptóticas na área de lesão nos períodos analisados. Além disso, os nossos resultados revelaram que os núcleos apoptóticos estão localizados principalmente nas camadas nucleares interna e externa e que o pico de núcleos em apoptose ocorre 1 dia após a lesão mecânica. 
Figura 12- Ensaio de TUNEL em retinas com lesões mecânicas.
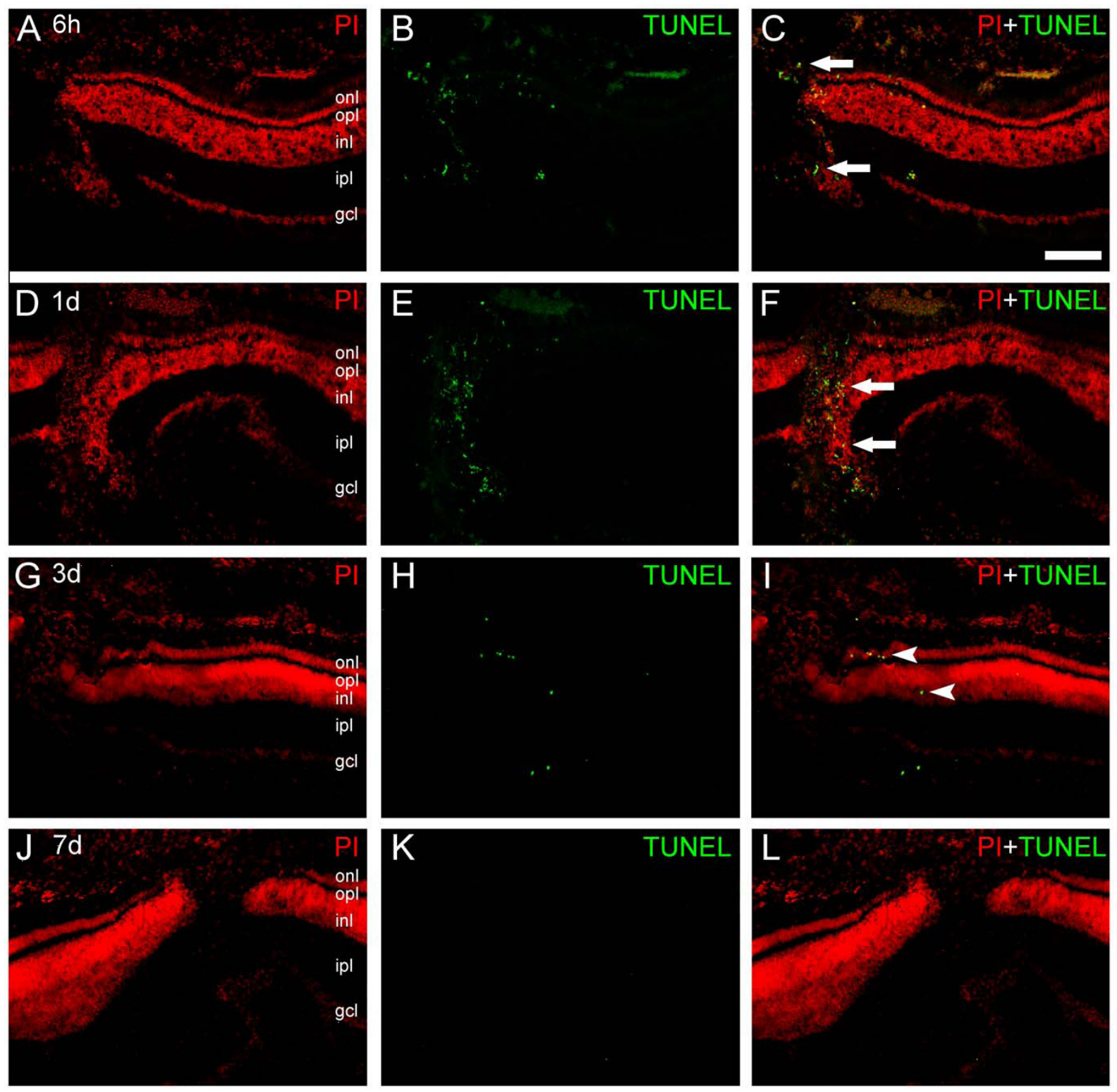

Seções transversais de retinas lesionadas foram submetidas ao ensaio de TUNEL (verde) para caracterizar o padrão espacial de apoptose. As retinas foram contracoradas com iodeto de propídio (PI, vermelho). A-C, 6h após o trauma mecânico pudemos observar núcleos de células TUNEL-positivas no foco da lesão (setas). D-F, em retinas após 1 dia de lesão, observamos um pico no número de células TUNEL-positivas, localizadas principalmente no foco da lesão. Estas células foram principalmente distribuídas na camada nuclear interna (INL), mas também na camada nuclear externa (ONL). Notou-se que algumas células localizadas na parte inferior da imagem saíram, na verdade, da INL e deslocaram-se pelo trauma mecânico. G-I, em retinas com lesões de 3 dias, observamos uma diminuição no número de células TUNEL-positivas. Além disso, estas células estavam localizadas longe do foco, na área de penumbra (cabeças de seta), evidenciando a morte celular secundária. Em retinas com 7 dias de lesão, observamos pouca ou nenhuma célula TUNEL-positiva. Barra de escala: $60 \mu \mathrm{M}$.

Fonte: Paschon et al., 2012. 


\subsection{Marcação de Cx36 foi observada nas proximidades de células apoptóticas}

Nossos resultados indicam que o pico de morte celular ocorre um dia após a lesão, e que as células apoptóticas concentram-se nas camadas nucleares interna e externa. A combinação destes resultados com a análise da distribuição espacial de Cxs levou-nos a suspeitar que a Cx36, mas não a Cx43, poderia provavelmente ter importante participação na degeneração de células da retina no modelo de lesão mecânica. Assim, realizamos experimentos para investigar se as células em apoptose expressam Cx36 concomitantemente com a marcação de TUNEL. Com este ensaio, detectamos núcleos TUNEL-positivo perto de marcação puntiforme de Cx36, indicando que as células em apoptose podem acumular Cx36 (Fig. 14A). É importante lembrar que a Cx36 está presente em processos de neurônios e não no núcleo, por isso não vemos co-localização das duas marcações. Com a ampliação de áreas específicas, observamos uma relação espacial próxima entre a Cx36 e as células TUNEL-positivas (Fig. 14, B-E). Detectamos núcleos TUNEL-positivos localizados na camada nuclear externa, rodeados por marcação de Cx36. Observamos também, núcleos TUNEL-positivo ao longo da camada nuclear interna, incluindo as células situadas tanto na margem interna e externa desta camada. Este padrão espacial revelou que diferentes tipos de células da retina expressam Cx36 em processo de apoptose. 
Figura 13- Relação espacial entre a Cx36 e núcleos TUNEL-positivos no foco e penumbra da lesão.
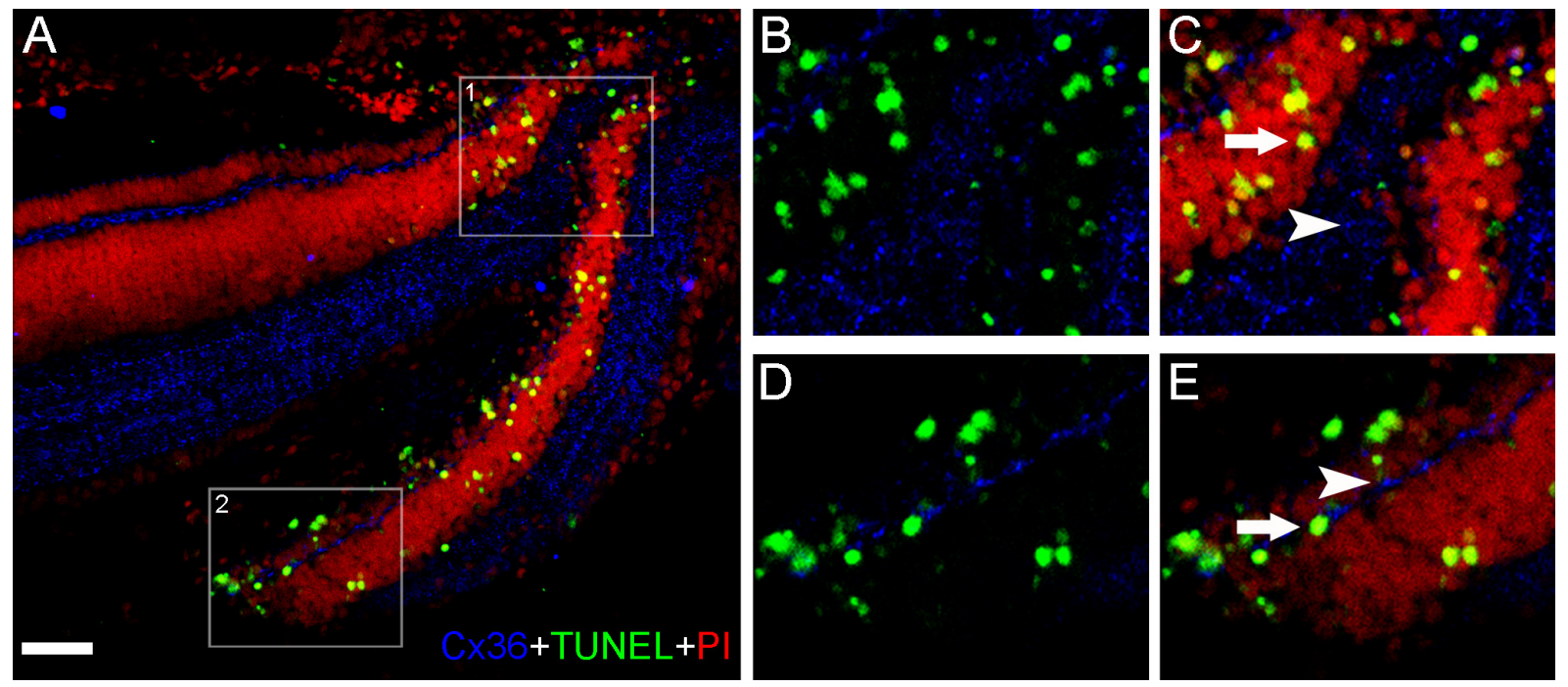

A fim de determinar a relação espacial entre Cx36 e núcleos TUNEL-positivos, o ensaio de TUNEL (verde) foi realizado em retinas após 1 dia de lesão, juntamente com a imunofluorescência para Cx36 (azul) e contracoloração com iodeto de propídio (PI, vermelho). (A) Observamos núcleos TUNEL-positivo perto da marcação puntiforme de Cx36, indicando que as células apoptóticas podem acumular Cx36. Com alta ampliação de áreas selecionadas 1-2, observamos a estreita relação espacial entre a marcação da Cx36 e núcleos TUNEL-positivos. (B, C) Detectamos muitos núcleos TUNEL-positivo localizados na camada nuclear externa (setas) rodeados por Cx36. (D, E) Além disso, observamos núcleos TUNEL-positivos ao longo da camada nuclear interna, incluindo as células localizadas na margem externa (setas), mas também na margem interna desta camada. Este padrão espacial revelou que diferentes tipos de células retinianas expressam Cx36 durante a apoptose. Barra de escala: $50 \mu \mathrm{M}$.

Fonte: Paschon et al., 2012.

\subsection{Células amácrinas expressam Cx36 durante o processo de apoptose}

Uma vez detectados núcleos TUNEL-positivos na camada INL da retina, realizamos experimentos de tripla-marcação para determinar se os neurônios que estão em processo de apoptose expressam Cx36. Para este fim, utilizamos o anticorpo produzido contra colina-acetiltransferase (ChAT), enzima encontrada em neurônios colinérgicos no sistema nervoso central. Como mostrado na Figura 15, a Cx36 exibiu a marcação puntiforme habitual. Na retina de pintos, o anti-ChAT marca células espelhadas da população de células amácrinas: 1) corpos de células amácrinas localizados na camada nuclear interna, cujos processos arborizam na subcamada 2 da camada plexiforme interna, e 2) corpos de células amácrinas deslocadas localizados na camada de células ganglionares, cujos processos 
arborizam na subcamada 4 da camada plexiforme interna. Em estudos anteriores observamos que a Cx36 encontra-se acumulada em processos de células amácrinas (Kihara et al., 2009). Neste estudo, observamos a marcação de Cx36 em células ChAT- e TUNEL-positivas. Estes resultados confirmaram que pelo menos uma população específica de células amácrinas expressa Cx36 durante o processo de apoptose. Além disso, podemos observar nas setas células amácrinas ChATpositivas em apoptose enquanto nas cabeças de setas observamos células amácrinas ChAT-positivas que ainda não entraram em apoptose por estarem localizadas mais distantes da lesão. Como estas células estão acopladas, em questão de tempo elas podem entrar em apoptose também.

Figura 14- Expressão de Cx36 em neurônios específicos durante o processo de apoptose.
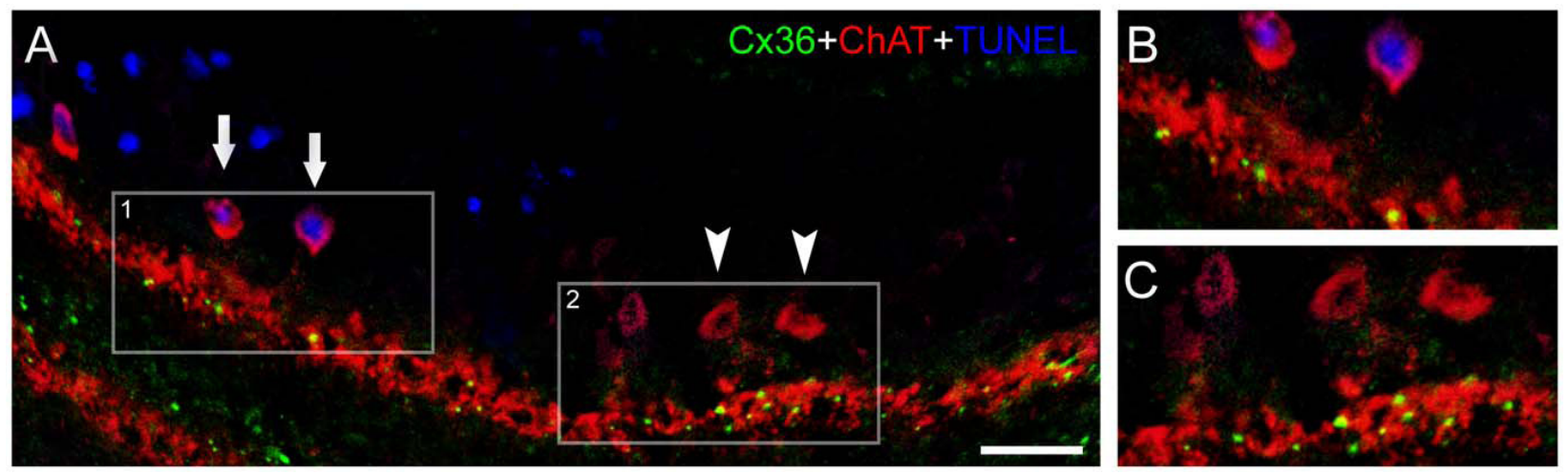

(A) A fim de confirmar a presença da Cx36 em neurônios específicos durante o processo de apoptose, realizamos experimentos de tripla-marcação para localizar simultaneamente a marcação de Cx36 (verde), colina acetiltransferase (ChAT, vermelho) e núcleos TUNELpositivos (azul) em cortes transversais de retinas após 1 dia de lesão. Na ampliação de áreas selecionadas 1 e 2, é possível observar co-localização de Cx36 e processos de células ChAT-positivas. (B) Com efeito, a marcação puntiforme típica de Cx36 foi observada nos processos de células amácrinas colinérgicas em processo de apoptose (setas). (C) Tal como esperado, a marcação puntiforme da Cx36 também foi observada em processos de células ChAT-positivas que não estavam em processo de apoptose (pontas de seta). Estes resultados confirmaram que as células amácrinas colinérgicas continuam expressando $\mathrm{C} \times 36$ durante o processo de apoptose. Barra de escala: $60 \mu \mathrm{M}$.

(B) Fonte: Paschon et al., 2012. 


\subsection{Bloqueadores de JCs aumentam a viabilidade celular em explantes de retina}

Além de determinar as alterações na expressão e distribuição de Cxs, também estudamos o papel funcional das Cxs mediando a comunicação neste modelo de degeneração da retina. Para este fim, foram avaliados os efeitos de bloqueadores (CBX e quinina) e abridores (TMA) de JCs em explantes de retina (Seigel, 1999, Koizumi et al., 2007). Retinas com lesões de 1 dia foram cultivadas em meio de cultura e amostras do meio foram coletadas após 1, 2 e 4 horas. Todos os ensaios realizados com concentrações mais baixas $(50 \mu \mathrm{M})$ não apresentaram mudanças significativas na liberação de LDH (Fig. 16, A-D). Por outro lado, a utilização de bloqueadores de JCs na concentração de $100 \mu \mathrm{M}$ reduziu a liberação de LDH pelos explantes no meio de cultura. A incubação de retinas com 0 bloqueador de JCs de amplo espectro CBX (Fig. 16E) teve diminuição significativa na liberação de LDH após $4 \mathrm{~h}(222,1 \%, \mathrm{P}<0,01)$. Em experimentos realizados com quinina (Fig. 16F), bloqueador específico de Cx36 e Cx50, observamos um efeito mais imediato, com poucas horas de incubação. Retinas incubadas com quinina liberaram menos LDH do que os controles a partir de $1(230,6 \%, P<0,01), 2$ $(227,9 \%, P<0,01)$ e $4 h(238,9 \%, P<0,01)$. A combinação de CBX e quinina (Fig. $16 \mathrm{G})$ também resultou na diminuição da liberação de LDH em todos os períodos analisados, 1 (221,1\%, $\mathrm{P}<0,01), 2(220,9 \%, \mathrm{P}<0,01)$ e $4 \mathrm{~h}(216,1 \%, \mathrm{P}<0,01)$. Por outro lado, experimentos realizados com o abridor de JCs TMA indicaram que não há mudanças significativas na liberação de LDH (Fig. 16H). 
Figura 15- Avaliação da viabilidade celular utilizando a quantificação de lactato desidrogenase (LDH) liberada pelas retinas lesionadas tratadas com bloqueadores e abridores de JCs.

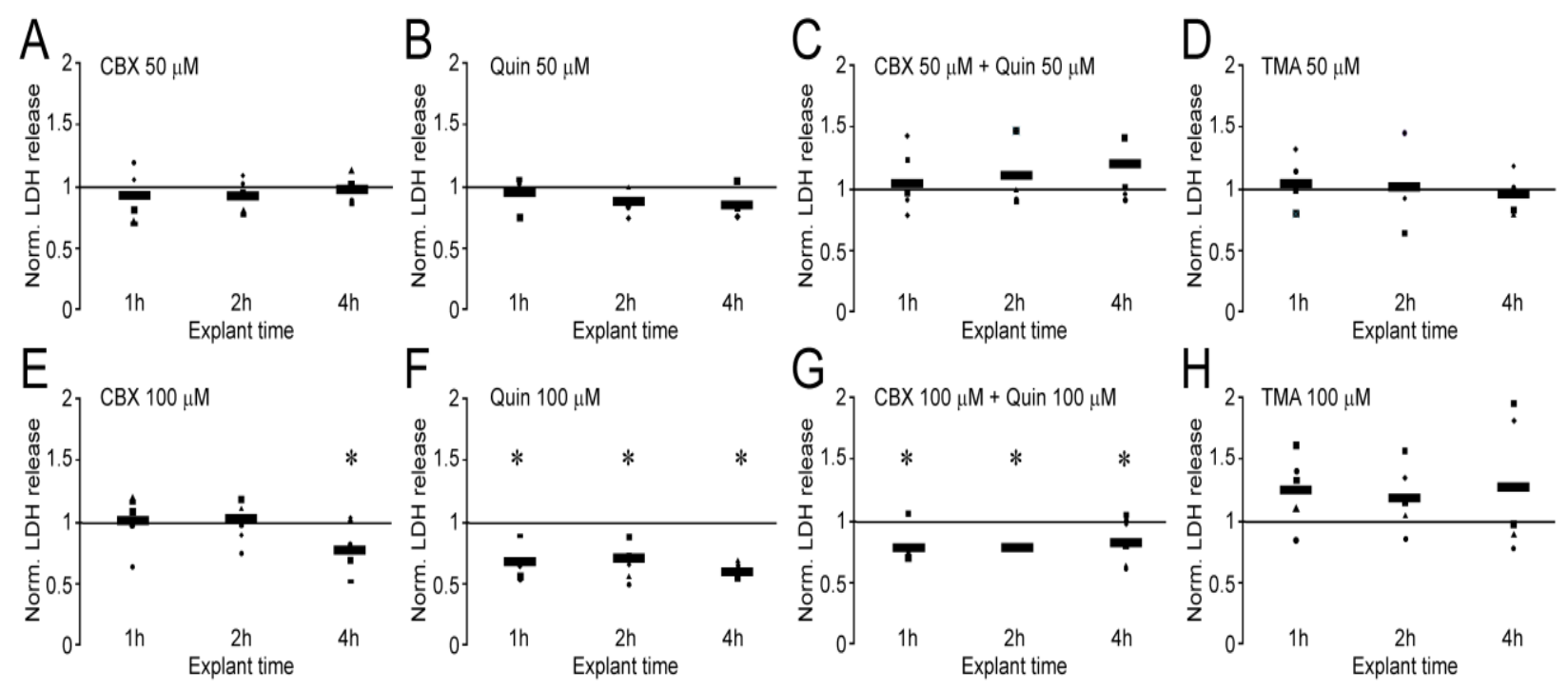

Retinas foram removidas após 1 dia de trauma mecânico binocular. Uma retina foi condicionada em meio contendo PBS (controle), enquanto que a outra foi condicionada em meio contendo agentes farmacológicos (experimental), que agem no fechamento (cabenoxolone, CBX, quinina) ou abertura (trimetilamina, TMA) dos canais de JCs. Os pontos do gráfico indicam a quantidade de LDH liberado por retinas lesadas normalizadas pelos respectivos controles, barras horizontais representam a média. Em alguns casos, os pontos experimentais sobrepõem uns aos outros e/ou a barra horizontal. Foram testadas

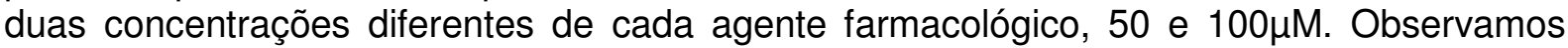
que não houve alterações na liberação de LDH em explantes de retina tratadas com (A) $\mathrm{CBX} 50 \mu \mathrm{M}$, (B) quinina $50 \mu \mathrm{M},(\mathrm{C}) \mathrm{CBX}+$ quinina $50 \mu \mathrm{M}$ e (D) TMA $50 \mu \mathrm{M}$. Por outro lado, observamos diminuição na liberação de LDH em retinas tratadas com bloqueadores de JCs na concentração de $100 \mu \mathrm{M}$. (E) Após 4 horas de incubação com CBX 100 $\mu \mathrm{M}$, verificamos uma redução significativa na liberação de $\mathrm{LDH}(222 \%, \mathrm{P}<0,01)$. (F) A incubação com quinina $100 \mu \mathrm{M}$ diminuiu a liberação de LDH a partir de $1 \mathrm{~h}(231 \%, \mathrm{P},<0,01), 2 \mathrm{~h}(228 \%, \mathrm{P}<0,01)$ e $4 \mathrm{~h}$ $(39 \%, P<0,01)$. (G) CBX + quinina $100 \mu \mathrm{M}$ tiveram resultados semelhantes: a libertação de LDH diminuiu após $1 \mathrm{~h}(221 \%, \mathrm{P}<0,01), 2 \mathrm{~h}(221 \%, \mathrm{P}<0,01)$ e $4 \mathrm{~h}(216 \%, \mathrm{P}<0,01)$ quando comparado as retinas controles. $(H)$ Não observamos mudança significativa na liberação de $\mathrm{LDH}$ usando TMA $100 \mu \mathrm{M}$ em qualquer um dos períodos analisados. ${ }^{*} \mathrm{P}<0,01 \mathrm{em}$ Teste $\mathrm{T}$ emparelhado $(n=5)$.

Fonte: Paschon et al., 2012. 


\subsection{Bloqueadores de JCs diminuem a expressão gênica de caspases durante a degeneração retiniana}

Considerando as evidências de nossos resultados in vitro, decidimos investigar os efeitos de bloqueadores de JCs na expressão gênica de caspases. Explantes de retina com lesões de um dia foram mantidos em cultura durante 4 horas, com bloqueadores de JCs ou PBS. Após este período, as retinas foram processadas para a técnica de PCR em tempo real. Como mostrado na Figura 18, observamos a diminuição da expressão do gene da caspase-3 em explantes de retina cultivados com quinina $(-69 \%, P<0,01)$ e $C B X+$ quinina $(-73 \%, P<0,01) . A$ caspase-8 também apresentou diminuição da expressão quando incubada com CBX $(-54 \%, P<0,05)$, quinina $(-58 \%, P<0,05)$ e $C B X+$ quinina $(-63 \%, P<0,05)$. Semelhantemente, as caspases-3 e 9 tiveram diminuição da expressão gênica apenas quando incubada com quinina $(-63 \%, P<0,01)$ e $C B X+$ quinina $(-64 \%$, $\mathrm{P}<0,01)$. Estes resultados revelaram que o tratamento com bloqueadores de JCs diminuíram a expressão gênica de ambas as caspases iniciais e efetoras, mas de forma específica e diferenciada. Com efeito, o tratamento com CBX afetou principalmente a expressão de caspase-8, enquanto que a quinina afetou as outras caspases estudadas (Fig. 17, A-D). 
Figura 16- Expressão gênica de caspases em explantes de retinas lesionadas tratados com bloqueadores de JCs.
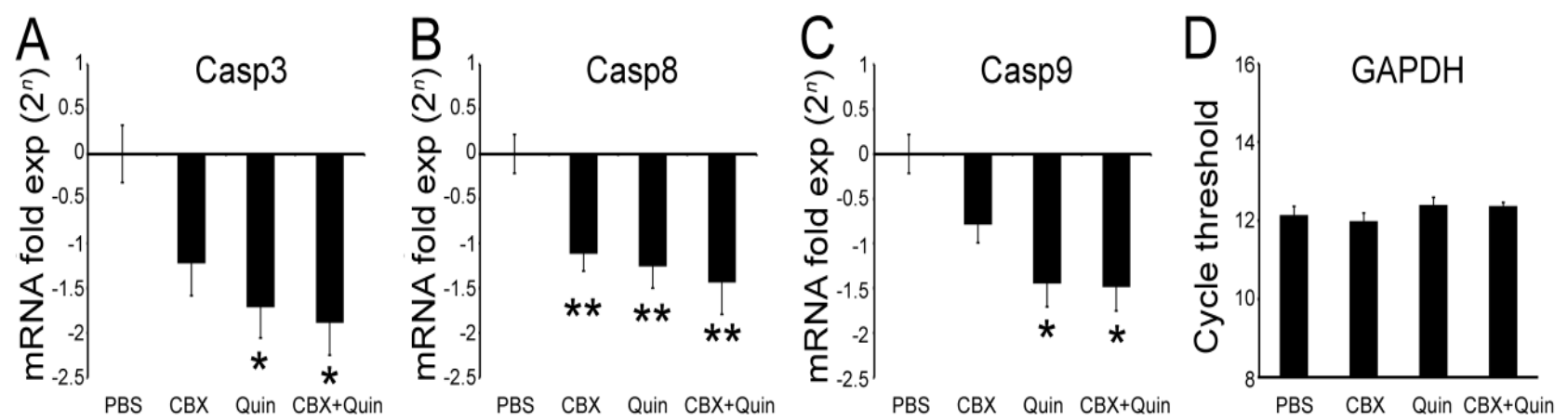

Retinas após 1 dia de lesão, foram incubadas com PBS, carbenoxolone (CBX), quinina

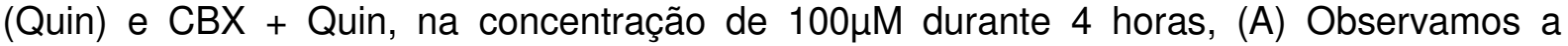
diminuição da expressão gênica da caspase $3 \mathrm{em}$ explantes de retinas incubadas com Quin $(269 \%, P<0,01)$ e CBX + Quin $(273 \%, P<0,01)$. (b) $A$ expressão gênica da caspase 8 diminuiu com o tratamento com CBX $(254 \%, P<0,05)$, Quin $(258 \%, P, 0,05)$ e CBX + Quin $(263 \%, P<0,05)(C)$ Similar à caspase 3 , a expressão gênica da caspase 9 diminuiu com 0 tratamento com Quin (263\%, $\mathrm{P}<0,01)$ e CBX + Quin (264\%, $\mathrm{P}<0,01)$. Todos os resultados foram normalizados pela média do grupo controle (PBS), e foram apresentados como expressão exponencial $\left(2^{n}\right)$. (D) A abundância de GAPDH foi utilizada como controle interno. Barras representam o erro padrão das médias. ${ }^{*} \mathrm{P}<0,01 \mathrm{e}{ }^{* *} \mathrm{P}<0,05$ vs PBS em ANOVA uma via seguida de comparações de pares de Newman-Keuls.

Fonte: Paschon et al., 2012.

\subsection{Bloqueadores de JCs limitam o espalhamento da apoptose in vitro}

Uma vez que os nossos resultados indicaram que a utilização de bloqueadores de JCs aumenta a viabilidade celular em retinas lesionadas, investigamos também se estes bloqueadores podem alterar a distribuição de células em processo de apoptose. Assim, retinas após 1 dia de leão foram dissecadas e incubadas com bloqueadores de JCs ou PBS por 4 horas. Após esse período, os explantes foram fixados e cortados em criostato para obtenção de lâminas para o ensaio de TUNEL. Tomando o foco da lesão como referência, a distribuição de núcleos TUNEL-positivos foi restrita em retinas incubadas com bloqueadores de JCs (Fig. 18, A-D), embora tenhamos observado algumas variações na distribuição espacial. Para testar a consistência deste resultado, foram empregados dois diferentes métodos de quantificação. Primeiro, traçamos um gráfico do número de núcleos TUNEL-positivos contados a partir de diferentes distâncias do foco da lesão. Em seguida, os dados foram submetidos a uma regressão linear usando mínimos quadrados, parâmetros de geração, como $R^{2}, R$ e também a equação de primeira 
ordem $(\mathrm{y}=\mathrm{ax}+\mathrm{b})$ para cada condição experimental (Fig. 18, E-H). Como uma segunda abordagem, os valores a partir da análise pixel a pixel foram submetidos ao mesmo procedimento (Fig. 18, I-L). A análise de pixels foi utilizada para quantificar a fluorescência em formato numérico, em que os valores correspondem ao brilho dos pixels. O coeficiente angular da equação de primeiro grau (a) foi calculado para cada condição experimental $(n=3)$, como um parâmetro de propagação da apoptose. Quanto ao número de núcleos TUNEL-positivos (Fig. 18M), o valor absoluto do coeficiente angular foi maior para todas as condições avaliadas, utilizando bloqueadores de JCs: CBX $(-1,83 \pm 0,35, P<0,05)$, quinina $(-1,90 \pm 0,26, P<0,01)$ e $\mathrm{CBX}+$ quinina $(-1,77 \pm 0,09, \mathrm{P}<0,01)$, quando comparadas com PBS $(-0.40 \pm 0,06)$. Da mesma forma, os valores obtidos a partir da análise pixel a pixel (Fig.18N) indicaram que as retinas incubadas com quinina $(-22,30 \pm 1,30, P<0,01)$ ou $C B X+$ quinina ($19,13 \pm 0,55, P<0,05)$, tiveram redução do brilho quando comparadas com PBS ($6,33 \pm 2,77)$. Tomados em conjunto, estes resultados revelaram que a propagação da apoptose é reduzida quando as retinas são tratadas com bloqueadores de JCs. 
Figura 17- Ensaio de TUNEL em explantes de retinas tratados com bloqueadores de JCs.
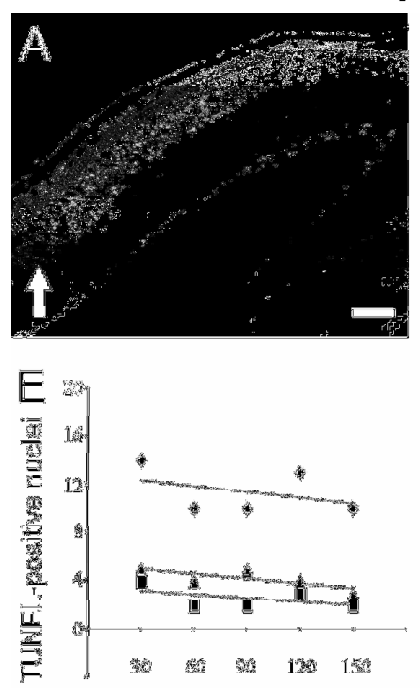

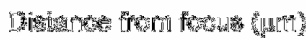

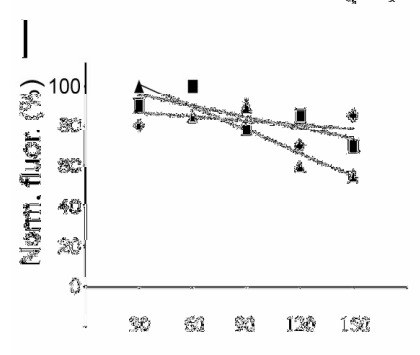

Istaro în fords (m)
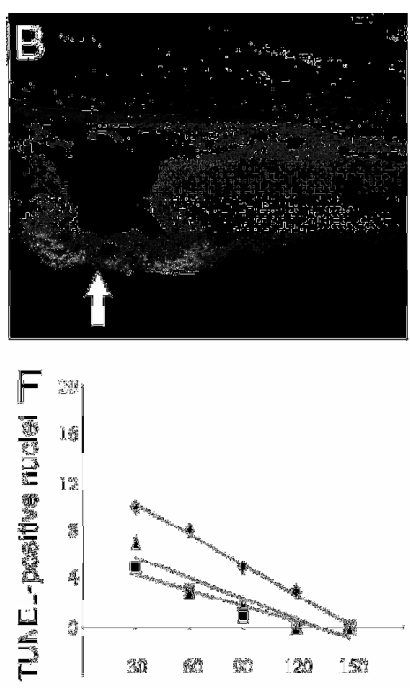

Distarin

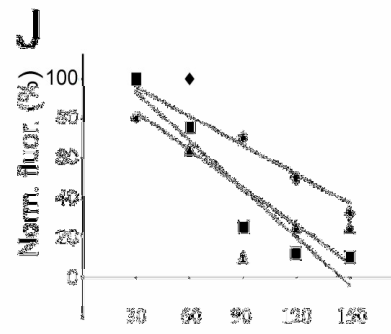

Sistance from towe

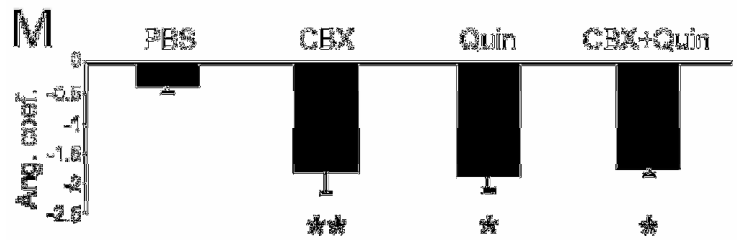

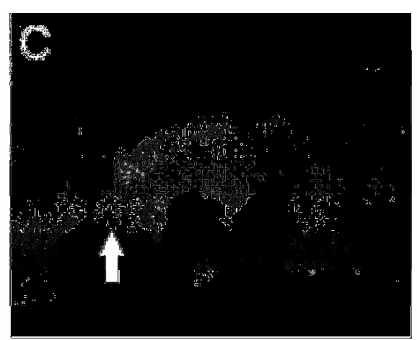
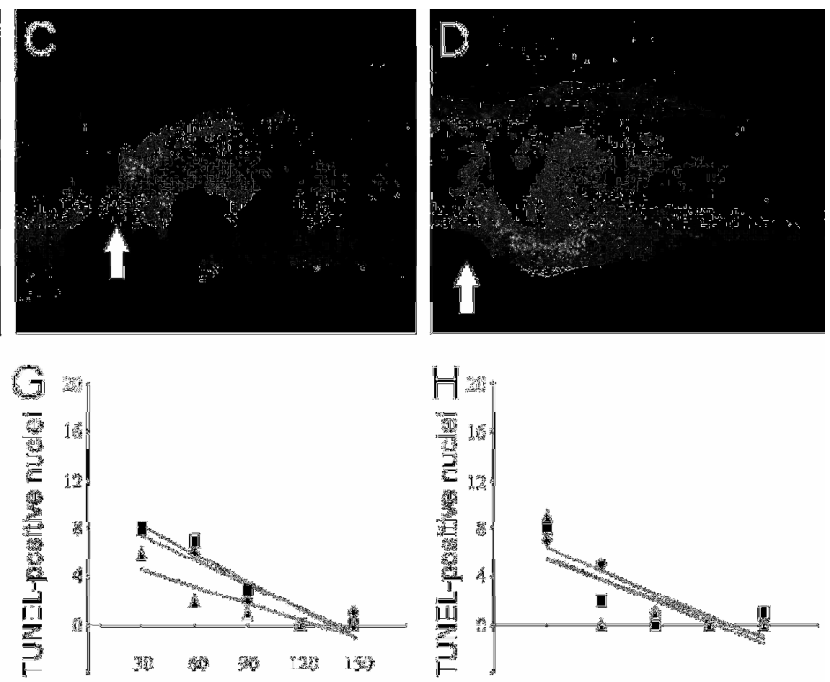

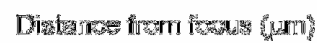

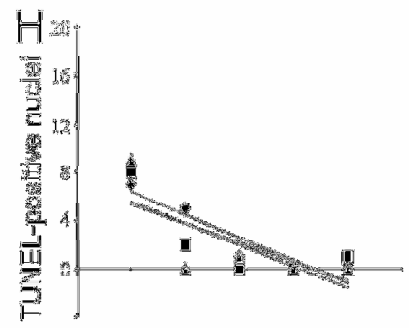

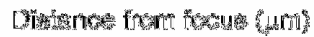

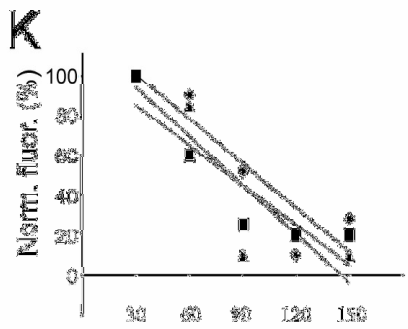

D stance fom focus (um)

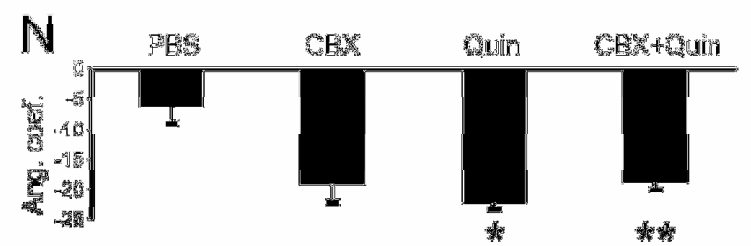

Explantes da retina foram incubados durante 4 horas com (A) PBS, (B) carbenoxolone

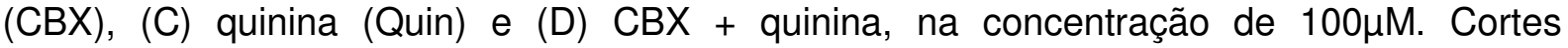
transversais de explantes de retina de pinto foram submetidos ao ensaio de TUNEL para caracterização do padrão espacial de espalhamento da apoptose. Em cada imagem, é possível localizar o foco da lesão (setas). (E-H) A fim de determinar se os bloqueadores de JCs causaram alterações na distribuição das células em apoptose, contamos o número de núcleos TUNEL-positivos localizados até $150 \mathrm{~mm}$ de distância do foco da lesão. Os valores foram calculados de acordo com a distância do foco, e foram submetidos à regressão linear usando a abordagem do método quadrado, gerando parâmetros matemáticos, como $\mathrm{R} 2, \mathrm{R}$ e também equação de primeira ordem $(y=a x+b)$. (I-L) $O$ mesmo procedimento foi realizado utilizando-se os valores a partir da análise pixel a pixel. (M) Considerando a distribuição de núcleos TUNEL-positivos, o coeficiente angular da equação de primeira ordem (a) foi calculado para cada condição experimental $(n=3)$ quando comparado com o controle (PBS), o coeficiente angular foi maior para todas as condições avaliadas, utilizando bloqueadores de JCs (CBX, quinina e CBX + quinina). (N) Em relação aos valores da análise pixel a pixel, observamos que o coeficiente angular foi maior para quinina e $C B X+$ quinina. ${ }^{*} P<0,01 e^{* *}$ $\mathrm{P}<0,05$ vs $\mathrm{PBS}$ em ANOVA uma via seguida de comparações de pares de Newman-Keuls. Barra de escala: $60 \mu \mathrm{M}$.

Fonte: Paschon et al., 2012. 


\subsection{Injeção intraocular de bloqueadores de JCs afeta no espalhamento da apoptose}

Uma vez que os nossos resultados indicaram que o tratamento in vitro com bloqueadores de JCs aumenta a viabilidade das células de retinas lesadas, decidimos investigar se esses bloqueadores também afetam a distribuição de células em processo de apoptose in vivo. Para este experimento, induzimos um trauma mecânico, seguido imediatamente por injeção de PBS ou bloqueadores de JCs. Após 1dia, os animais foram decapitados e as retinas foram dissecadas para obtenção de cortes transversais da retina para o ensaio de TUNEL. Como resultado geral, observamos alterações na distribuição de células em processo de apoptose em retinas tratadas com bloqueadores de JCs. A distribuição de núcleos TUNELpositivo se apresentou de forma mais restrita em retinas que receberam injeção de bloqueadores de JCs (Fig. 19, A-D). Mais uma vez, foram empregados dois métodos diferentes de quantificação: i) o número de núcleos TUNEL-positivos contados a partir de diferentes distâncias a partir do foco da lesão (Fig. 19, E-H) e ii) valores normalizados a partir da análise pixel a pixel (Fig. 19, I-L). Observamos que o coeficiente angular foi maior para quinina $500 \mu \mathrm{M}(-1,55 \pm 0,12, \mathrm{P}<0.05)$ e $\mathrm{CBX}+$ quinina $500 \mu \mathrm{M}(-1,63 \pm 0,18, \mathrm{P}<0.05)$ quando comparado com PBS $(-0,71 \pm 0,11)$. (N) Em relação aos valores da análise pixel a pixel, observamos que a média do coeficiente angular foi maior para retinas injetadas com quinina $500 \mu \mathrm{M}(-22,56 \pm 3,03$, $\mathrm{P}<0.05)$ quando comparado com PBS $(-11,98 \pm 2,04)$. Tomados em conjunto, estes resultados revelaram que a apoptose na retina após mecânica trauma é afetada por injeções intraoculares de bloqueadores GJ. 
Figura 18- Ensaio de TUNEL em retinas lesionadas com injeção de bloqueadores de JCs.
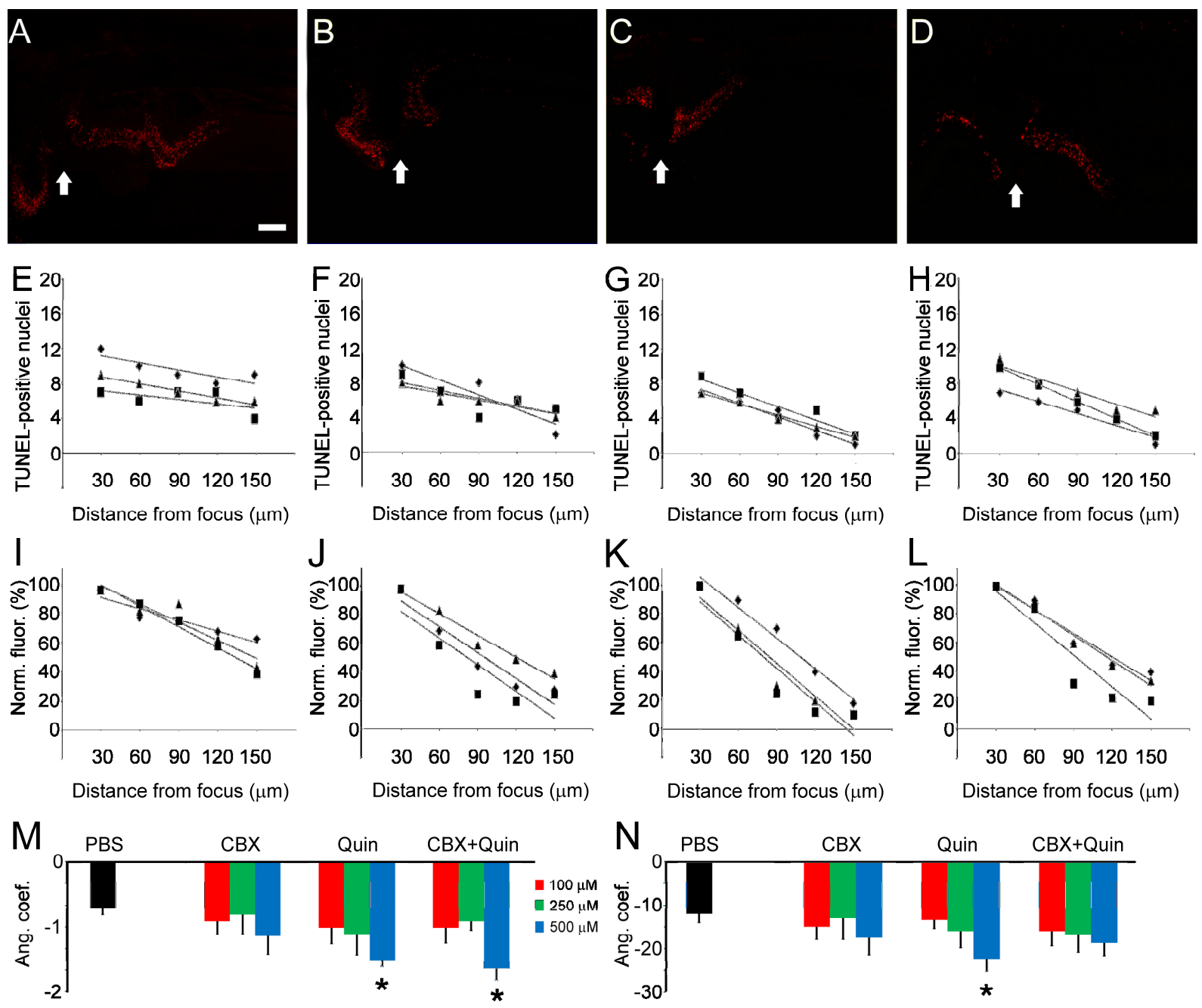

Imediatamente após o trauma mecânico na retina, realizamos injeções intravitreo de $(A)$ PBS, (B) carbenoxolone (CBX), (C) quinina (Quin) e (D) CBX + quinina na concentração de $500 \mu \mathrm{M}$. Os animais foram sacrificados 1 dia pós-lesão, e cortes transversais de retinas foram submetidos ao ensaio de TUNEL para caracterizar o padrão espacial da apoptose. Em cada imagem localizamos o foco da lesão (setas). (E-H) A fim de determinar se os bloqueadores de JCs causam alterações na distribuição das células apoptóticas, contamos o número de núcleos TUNEL-positivos localizados até $150 \mathrm{~mm}$ de distância do foco da lesão. Os valores foram plotados de acordo com a distância do foco, e foram submetidos a regressão linear para gerar parâmetros matemáticos tais como $R 2, R$ e também equação de primeira ordem $(y=a x+b)$. (I-L) O mesmo procedimento foi realizado utilizando-se os valores a partir da análise pixel a pixel. (M) Considerando a distribuição de núcleos TUNELpositivos, o coeficiente angular da equação de primeira ordem (a) foi calculado para cada condição experimental $(n=3)$. Quando comparado com o controle (PBS), o coeficiente angular foi maior para quinina $500 \mu \mathrm{M}$ e $\mathrm{CBX}+$ quinina $500 \mu \mathrm{M}$. $(\mathrm{N}) \mathrm{Em}$ relação aos valores da análise pixel a pixel, observamos que a média do coeficiente angular foi maior para retinas injetadas com $500 \mu \mathrm{M}$ quinina. * $\mathrm{P}<0,05$ vs PBS em comparações de pares de Newman-Keuls após ANOVA de dois fatores. Barra de escala: $60 \mu \mathrm{m}$.

Fonte: Paschon et al., 2012. 
Grande parte dos resultados apresentados acima foram publicadas no artigo "Blocking of connexin-mediated communication promotes neuroprotection during acute degeneration induced by mechanical trauma." de autoria de Paschon V, Higa GS, Resende RR, Britto LRG, Kihara AH (2012), publicado na PloS one 9:e45449 (ANEXO B). O resultado sobre gliose reativa na lesão de 7 dias faz parte do artigo " $A$ new and reliable guide for studies of neuronal loss based on focal lesions and combinations of in vivo and in vitro approaches." de autoria de Paschon V, Higa GS, Walter LT, de Sousa E, Zuzarte FC, Weber VR, Resende RR, Kihara AH (2013), publicado na revista PloS one 8:e60486 (ANEXO A). 


\section{DISCUSSÃO}

O trauma mecânico localizado no $\mathrm{SN}$ resulta primeiramente em perda de células, seguido do espalhamento da morte celular secundária. Esse evento secundário pode levar a uma maior perda de neurônios do que o evento proveniente do insulto primário (Hall, Yonkers, 1989). A participação das JCs na morte celular secundária à lesão tem sido examinada em muitas patologias incluindo o câncer (Decrock et al., 2009; Mesnil et al., 1996). Entretanto, o envolvimento do acoplamento celular no espalhamento da apoptose pode ser investigado seguindo algumas premissas. Primeiro, as células devem estar amplamente e efetivamente acopladas; segundo, as células em apoptose devem expressar Cxs; terceiro, o modelo de estudo deve gerar gradiente de concentração entre as células, a fim de se comparar o foco com a penumbra e as áreas adjacentes à lesão. Sabe-se que as células da retina são extensivamente acopladas por canais de JCs, formando longas redes de comunicação (Bloomfield, Volgyi, 2009; Kihara et al., 2006; Kihara et al., 2008). Com efeito, a permeabilidade dos canais e a expressão de Cxs podem ser moduladas em diversas condições fisiológicas, como durante o desenvolvimento da retina (Hennig et al., 2009; Kihara et al., 2006), mas também em resposta à adaptação à luz/escuro (Kihara et al., 2009). Diante destes resultados, evidenciando a plasticidade das sinapses elétricas, direcionamos nossos esforços para a regulação da expressão de Cxs durante a neurodegeneração aguda.

Na primeira parte deste estudo, determinamos que a Cx36 teve os níveis de expressão gênica constante e a $\mathrm{C} \times 43$ teve uma regulação positiva e significativa após 7 dias de lesão. Os níveis proteicos de Cx36 diminuíram após 3 e 7 dias enquanto que os níveis proteicos da $\mathrm{C} \times 43$ aumentaram significativamente após 7 dias, seguindo um padrão parecido com a avaliação da expressão gênica. $A$ análise por imunofluorescência revelou que, apesar das mudanças específicas na distribuição espacial de ambas as proteínas, a marcação foi observada no foco e penumbra da lesão sugerindo a participação destas proteínas no evento neurodegenerativo. A C×36 não teve mudança clara na distribuição espacial, porém a Cx43 apresentou aumento da marcação e uma desorganização gradativa após cada período de lesão, principalmente após 7 dias. Coincidentemente, experimentos para determinar a gliose reativa decorrente da lesão, indicaram um aumento para proteína fibrilar glial (GFAP) no foco da lesão após 7 dias. Possivelmente, o aumento 
na imunorreatividade para Cx43 tem íntima relação com o aumento de GFAP. Estes achados corroboram com estudos sobre injúrias no $\mathrm{SN}$, que descreveram uma definida resposta de astrócitos, consistindo em rápida proliferação, hipertrofia e aumento da expressão de GFAP, concomitantemente com a regulação positiva da expressão de Cx43 (Rouach et al., 2002). Essa gliose reativa está relacionada à função das células de Muller na retina em tentar manter a homeostase e proteger os neurônios da excessiva liberação de neurotransmissores que podem ser citotóxicos e ter efeito antioxidante em altas concentrações (Vidal et al., 2010).

No intuito de caracterizar o padrão de espalhamento da apoptose ao longo dos períodos pós-lesão, realizamos ensaios de TUNEL após 6h, 1 dia, 3 dias e 7 dias. Observamos que no momento inicial da lesão, ocorre principalmente morte celular por necrose, independente de caspases, isso porque 6h após a lesão já podemos observar núcleos de células apoptóticas, mas ainda em pouca quantidade quando comparamos com lesões de 1 dia, onde ocorre o pico de apoptose neste modelo de lesão. Após 3 dias, a quantidade de núcleos TUNEL-positivos diminui drasticamente e estes se encontram mais afastados do foco da lesão indicando espalhamento da apoptose para as áreas adjacentes à lesão. Após 7 dias, quase não observamos marcação de TUNEL na retina lesada. Esses achados vão de encontro com o estudo de Striedinger (2005), que fez lesões por laser na retina e observou um aumento gradativo de núcleos TUNEL-positivos de 2 até $24 \mathrm{~h}$. Estes autores relataram que após 2 dias ocorre diminuição e 3 dias depois da lesão já não era possível ver núcleos apoptóticos na região lesada. Mesmo considerando a natureza distinta dos insultos, o curso temporal do espalhamento da apoptose parece seguir padrões semelhantes.

Como o pico de apoptose ocorre por volta de $24 \mathrm{~h}$, escolhemos este período pós-lesão para realizar os próximos experimentos, tanto de dupla e tripla-marcação com TUNEL, quanto experimentos funcionais. Os experimentos de dupla-marcação mostraram que a Cx36 encontra-se acumulada perto de núcleos TUNEL-positivos, revelando a presença desta proteína nas células apoptóticas, ou na sua vizinhança. Não foi possível observar co-localização porque as Cxs são proteínas de membrana que não se acumulam nos núcleos. Experimentos de tripla-marcação com ChAT confirmaram que a Cx36 está presente em neurônios apoptóticos e que há células saudáveis na vizinhança que podem estar acopladas com esses neurônios. Nosso 
grupo de estudo já havia descrito previamente a expressão de Cx36 em células amácrinas colinérgicas na retina de pintinhos (Kihara et al., 2009).

O papel funcional do acoplamento celular pelas JCs foi avaliado com bloqueadores e abridores farmacológicos, levantando questões habituais, como a toxicidade celular e especificidade de ação. CBX, um bloqueador de JCs de amplo espectro, tem sido utilizado em estudos sobre a retina, onde nenhum efeito tóxico significativo foi relatado (Kihara et al., 2010 - ANEXO C; Vaney et al., 1998). Nossos resultados indicaram que a utilização de CBX aumentou a viabilidade celular in vitro, diminuindo o espalhamento da apoptose. CBX é um derivado sintético do ácido glicirretínico, um triterpenóide pentacíclico com diversas propriedades farmacológicas, incluindo ações antivirais, antifúngicas, antiprotozoário e atividade anti-bacteriana. Além disso, sabe-se que o CBX pode atuar sobre canais de cálcio dependentes de voltagem na retina (Vessey et al., 2004). Para contornar este problema, utilizamos uma classe diferente de moléculas, que também atua na comunicação mediada por Cxs. A quinina, um alcalóide que bloqueia especificamente canais formados pelas Cx36 e Cx50, promove alterações de permeabilidade das JCs por mecanismos distintos (Srinivas et al., 2001). Experimentos utilizando a quinina como bloqueador de JCs no modelo de lesão por trauma mecânico, indicaram que o bloqueio dos canais de JCs, muito provavelmente formados por Cx36, proporciona aumento da sobrevivência neuronal. Na verdade, os efeitos protetores da quinina foram observados num tempo mais curto (1h) do que usando apenas o CBX (4h). A combinação de CBX com quinina resultou em diminuição do espalhamento da morte celular secundária à lesão, tão rapidamente quanto utilizando somente quinina, indicando que possivelmente houve somação dos efeitos e que o efeito da quinina foi mais significativo e rápido do que o do CBX. Tomados em conjunto, estes resultados indicaram que o CBX poderia bloquear diferentes Cxs, inclusive canais formados por Cx43 em astrócito. Este bloqueio poderia ter efeito neuroprotetor, considerando o espalhamento de moléculas tóxicas em altas concentrações, como $\mathrm{Ca}^{2+}$ e glutamato em um sincício panglial. Por outro lado, a quinina Cx36 neuronal impediria a difusão de produtos provenientes da apoptose para neurônios sadios. Nossos resultados indicaram que as propriedades bloqueadoras do alcalóide de quinina podem ser bastante úteis, embora muito provavelmente em situações específicas, distintas, como demonstradas na neurodegeneração aguda. Realizamos também experimentos com TMA 
(trimetilamina, base nitrogenada), um abridor de JCs de amplo espectro, e observamos um aumento no espalhamento da apoptose, embora não significativo para as doses e tempo de ação empregados.

Estudos sobre o bloqueio de Cxs em cultura de glioma mostraram que os canais e hemicanais de Cxs podem atuar de duas maneiras diferentes: primeiro, permitindo a liberação de moléculas citotóxicas das células apoptóticas, que podem se difundir no meio extracelular ou podem se difundir no sincício panglial, formado pelo acoplamento glial, aumentando as chances de sobrevivência neuronal; segundo, levar a entrada de segundos mensageiros pró-apoptóticos em células saudáveis ou deixar que metabólitos essenciais saiam das células fazendo com que estas células vizinhas ou remotas entrem em apoptose. Existe um equilíbrio entre a neuroproteção e neurodegeneração. Quando ocorre morte excessiva de células, esse equilíbrio é perturbado resultando em um domínio da apoptose sobre os sinais de sobrevivência (Decrock et al., 2009). No caso da lesão mecânica, muitas células morrendo podem fazer com que as células vizinhas entrem em apoptose, mas outras células saudáveis poderiam resgatar algumas células que estariam entrando em apoptose.

Considerando que a utilização de bloqueadores diminuiu a propagação da apoptose em um modelo de trauma mecânico agudo, pode ser de grande valia a identificação de moléculas apoptóticas que foram afetadas por esses bloqueadores. Nossos resultados mostraram que os níveis de RNAm de caspases iniciais, como a caspase-8 foram significativamente menores no tratamento com bloqueadores de JCs quando comparadas às retinas que foram incubadas com PBS. Para caspases efetoras, como a caspase-9 e caspase-3, o tratamento com CBX não alterou os níveis de RNAm, mas o tratamento com quinina e a combinação dos dois bloqueadores diminuiu os transcritos de RNAm. Esses resultados evidenciam a diminuição da apoptose clássica mediada por caspases nas retinas tratadas com bloqueadores. Em geral, diversos mecanismos de degeneração secundária têm sido propostos, incluindo liberação de radicais livres de oxigênio, alteração das concentrações de íons extracelulares, níveis elevados de glutamato e cálcio intracelular (Fujihara et al., 2008; Kermer et al., 1999; Lynch, Dawson, 1994). Em relação à comunicação direta célula-célula, a concentração do cálcio parece ser particularmente importante, uma vez que é classicamente associado a apoptose no sistema nervoso, além disso, alterações rápidas na concentração de cálcio 
intracelular, causadas pelo acoplamento via JCs, foram claramente demonstrados na retina (Blankenship et al., 2011; Firth et al., 2005). A transferência de segundos mensageiros facilmente difusíveis por canais de JCs, como IP3, poderia controlar as concentrações de cálcio citosólico (Bosanac et al., 2002).

Alterações nos níveis de microRNAs também podem estar envolvidas na propagação da neurodegeneração e da apoptose. A passagem dessas pequenas moléculas, com cerca de 21 nucleotídeos (Saba et al., 2008, Schonrock et al., 2010), através de canais de JCs foi verificada recentemente em células neurais (Katakowski, Palliser, 2010). Diferenças na biogênese e degradação destes RNAs não-codificantes foram observadas em células que estão sofrendo apoptose (Bail et al., 2010). De fato, as alterações na expressão de miRNAs específicos podem induzir apoptose por mecanismos distintos, incluindo a via dependente de caspases (Chhabra et al., 2009). Embora especulativa esta hipótese é compatível com os resultados apresentados neste estudo e está sendo investigada por nosso grupo de pesquisa.

Finalmente, realizamos as lesões nos olhos dos pintinhos e, concomitantemente, injetamos bloqueadores em doses mais altas $(100,250$ e $500 \mu \mathrm{M})$ para avaliar a ação dos bloqueadores in vivo. Apenas a dose de $500 \mu \mathrm{M}$ teve efeito significativo in vivo, pois nessas condições torna-se mais difícil de controlar a quantidade de droga que chega para as células alvo. Os resultados observados foram parecidos com os do experimento in vitro, mas bem menos significativos. Isso por conta da dificuldade de controlar o experimento bem como pela diferença temporal do tratamento. No experimento in vitro, esperamos entre 12 e $24 \mathrm{hs}$ para retirar as retinas lesadas e incubar com os bloqueadores enquanto que, no experimento in vivo, lesamos e injetamos a droga ao mesmo tempo, com a mesma agulha para não causar grandes danos aos animais, então após 24hs suas retinas foram dissecadas para a análise de TUNEL.

Em resumo, o bloqueio de Cxs neuronais parece diminuir o espalhamento da apoptose enquanto que o bloqueio de Cxs gliais pode ter efeitos negativos. Embora sejam necessárias mais abordagens nesse campo, estes dados podem ser de grande valia para o desenvolvimento de novas terapias para o tratamento de lesões no SN. 


\section{CONCLUSÕES}

Nossos resultados indicaram importante modulação da expressão de Cxs nas diferentes fases da degeneração por trauma mecânico localizado na retina. Observamos uma diminuição da expressão gênica da Cx36 após 3 e 7 dias de lesão, enquanto que a $\mathrm{C} \times 43$ apresentou aumento da expressão gênica e proteica após 7 dias. A regulação da expressão destes genes sugere a participação do acoplamento celular em processos neurodegenerativos. Esta regulação diferenciada para as Cxs analisadas pode estar relacionada com a expressão destes genes por tipos celulares específicos da retina ou características específicas do acoplamento provido pelas diferentes Cxs. A expressão de GFAP foi regulada positivamente após 7 dias, coincidindo com a regulação positiva de Cx43. A Cx36 foi observada em células amácrinas colinérgicas em apoptose, assim como em células amácrinas mais distantes que ainda não entraram em apoptose. Bloqueadores de JCs parecem ter efeito neuroprotetor neste modelo de lesão aguda, na concentração de $100 \mu \mathrm{M}$ in vitro e na concentração de $500 \mu \mathrm{M}$ in vivo. A quinina ou a combinação de CBX e quinina, parecem ter uma ação mais rápida e eficaz em comparação com o CBX, tanto na diminuição da liberação de LDH quanto na diminuição da expressão gênica de caspases iniciais e efetoras, além da diminuição da quantidade de células TUNEL-positivas.

Desta forma, nossos resultados mostram que as Cxs podem ter efeitos distintos na neurodegeneração/neuroproteção dependendo do tipo celular, modelo de neurodegeneração mais generalizada ou focal gerando gradiente, modo como as JCs são inibidas ou bloqueadas. Mais importante, nossos resultados indicam que 0 bloqueio de JCs pode ajudar na busca de novas terapias contra o espalhamento de células em apoptose, processo comum às diversas doenças neurodegenerativas. 


\section{REFERÊNCIAS *}

Alzheimer C. Molecular and Cellular Biology of Neuroprotection in the CNS. AEMB. New York. 2002;513.

Bail S, Swerdel M, Liu H, Jiao X, Goff LA, Hart RP, Kiledjian M. Differential regulation of microRNA stability. Rna. 2010;16:1032-9.

Becker DL, Bonness V, Catsicas M, Mobbs P. Changing patterns of ganglion cell coupling and connexin expression during chick retinal development. Journal of Neurobiology. 2002;52:280-93.

Becker EB, Bonni A. Beyond proliferation--cell cycle control of neuronal survival and differentiation in the developing mammalian brain. Seminars in Cell \& Developmental Biology. 2005;16:439-48.

Ben-Sasson SA, Sherman Y, Gavrieli Y. Identification of dying cells--in situ staining. Methods in Cell Biology. 1995;46:29-39.

Bennett MV, Barrio LC, Bargiello TA, Spray DC, Hertzberg E, Saez JC. Gap junctions: new tools, new answers, new questions. Neuron. 1991;6:305-20.

Blanc EM, Bruce-Keller AJ, Mattson MP. Astrocytic gap junctional communication decreases neuronal vulnerability to oxidative stress-induced disruption of $\mathrm{Ca}+$ homeostasis and cell death. Journal of Neurochemistry. 1998;70:958-70.

Blankenship AG, Hamby AM, Firl A, Vyas S, Maxeiner S, Willecke K, Feller MB. The role of neuronal connexins 36 and 45 in shaping spontaneous firing patterns in the developing retina. The Journal of Neuroscience : the Official Journal of the Society for Neuroscience. 2011;31:9998-10008.

Bloomfield SA, Volgyi B. The diverse functional roles and regulation of neuronal gap junctions in the retina. Nature Reviews Neuroscience. 2009;10:495-506.

Bosanac I, Alattia JR, Mal TK, Chan J, Talarico S, Tong FK, Tong KI, Yoshikawa F, Furuichi T, Iwai M, Michikawa T, Mikoshiba K, Ikura M. Structure of the inositol 1,4,5trisphosphate receptor binding core in complex with its ligand. Nature. 2002;420:696700.

Bostanci MO, Bagirici F. Anticonvulsive effects of quinine on penicillin-induced epileptiform activity: an in vivo study. Seizure: the Journal of the British Epilepsy Association. 2007;16:166-72.

\footnotetext{
* De acordo com:

International Committee of Medical Journal Editors. [Internet]. Uniform requirements for manuscripts submitted to Biomedical Journal: sample references. [updated 2011 Jul 15]. Available from: http://www.icmje.org
} 
Bruzzone R, Ressot C. Connexins, gap junctions and cell-cell signalling in the nervous system. The European Journal of Neuroscience. 1997;9:1-6.

Charles A. Intercellular calcium waves in glia. Glia. 1998;24:39-49.

Chhabra R, Adlakha YK, Hariharan M, Scaria V, Saini N. Upregulation of miR-23a27a-24-2 cluster induces caspase-dependent and -independent apoptosis in human embryonic kidney cells. PloS One. 2009;4:e5848.

Church J, Baimbridge KG. Exposure to high-pH medium increases the incidence and extent of dye coupling between rat hippocampal CA1 pyramidal neurons in vitro. The Journal of Neuroscience : the Official Journal of the Society for Neuroscience. 1991;11:3289-95.

Cudeiro J, Rivadulla C. Sight and insight--on the physiological role of nitric oxide in the visual system. Trends in Neurosciences. 1999;22:109-16.

Danesh-Meyer HV, Kerr NM, Zhang J, Eady EK, O'Carroll SJ, Nicholson LF, Johnson CS, Green CR. Connexin43 mimetic peptide reduces vascular leak and retinal ganglion cell death following retinal ischaemia. Brain : a Journal of Neurology. 2012;135:506-20.

Dang L, Pulukuri S, Mears AJ, Swaroop A, Reese BE, Sitaramayya A. Connexin 36 in photoreceptor cells: studies on transgenic rod-less and cone-less mouse retinas. Molecular Vision. 2004;10:323-7.

de Pina-Benabou MH, Szostak V, Kyrozis A, Rempe D, Uziel D, Urban-Maldonado M, Benabou S, Spray DC, Federoff HJ, Stanton PK, Rozental R. Blockade of gap junctions in vivo provides neuroprotection after perinatal global ischemia. Stroke; a Journal of Cerebral Circulation. 2005;36:2232-7.

Deans MR, Volgyi B, Goodenough DA, Bloomfield SA, Paul DL. Connexin36 is essential for transmission of rod-mediated visual signals in the mammalian retina. Neuron. 2002;36:703-12.

Decrock E, Vinken M, De Vuyst E, Krysko DV, D'Herde K, Vanhaecke T, Vandenabeele P, Rogiers V, Leybaert L. Connexin-related signaling in cell death: to live or let die? Cell Death and Differentiation. 2009;16:524-36.

Firth SI, Wang CT, Feller MB. Retinal waves: mechanisms and function in visual system development. Cell Calcium. 2005;37:425-32.

Frantseva MV, Kokarovtseva L, Naus CG, Carlen PL, MacFabe D, Perez Velazquez JL. Specific gap junctions enhance the neuronal vulnerability to brain traumatic injury. The Journal of neuroscience : the Official Journal of the Society for Neuroscience. 2002;22:644-53.

Froes MM, Correia AH, Garcia-Abreu J, Spray DC, Campos de Carvalho AC, Neto MV. Gap-junctional coupling between neurons and astrocytes in primary central 
nervous system cultures. Proceedings of the National Academy of Sciences of the United States of America. 1999;96:7541-6.

Fujihara M, Nagai N, Sussan TE, Biswal S, Handa JT. Chronic cigarette smoke causes oxidative damage and apoptosis to retinal pigmented epithelial cells in mice. PloS One. 2008;3:e3119.

Furshpan EJ, Potter DD. Mechanism of nerve-impulse transmission at a crayfish synapse. Nature. 1957;180:342-3.

Giaume C, Kirchhoff F, Matute C, Reichenbach A, Verkhratsky A. Glia: the fulcrum of brain diseases. Cell Death and Differentiation. 2007;14:1324-35.

Giaume C, Leybaert L, C CN, J CS. Connexin and pannexin hemichannels in brain glial cells: properties, pharmacology, and roles. Front Pharmacol. 2013;4:88.

Goodenough DA, Revel JP. A fine structural analysis of intercellular junctions in the mouse liver. The Journal of Cell Biology. 1970;45:272-90.

Hall ED, Yonkers PA. Mechanisms of neuronal degeneration secondary to central nervous system trauma or ischemia. Journal of Neurotrauma. 1989;6:227-8.

Hengartner MO. The biochemistry of apoptosis. Nature. 2000;407:770-6.

Hennig MH, Adams C, Willshaw D, Sernagor E. Early-stage waves in the retinal network emerge close to a critical state transition between local and global functional connectivity. The Journal of Neuroscience: the Official Journal of the Society for Neuroscience. 2009;29:1077-86.

Higa GSV, Resende RR, Kihara AH. A Sinalização por Cálcio via junções comunicantes. In: Resende RR, Guatimosim S, Leite MF. Sinalização de cálcio: bioquímica e fisiologia celulares. São Paulo: Sarvier, 2012. v. 1, p. 103-21.

Jaattela M, Tschopp J. Caspase-independent cell death in T lymphocytes. Nature Immunology. 2003;4:416-23.

Jiang JX, Gu S. Gap junction- and hemichannel-independent actions of connexins. Biochimica et Biophysica Acta. 2005;1711:208-14.

Joza N, Susin SA, Daugas E, Stanford WL, Cho SK, Li CY, Sasaki T, Elia AJ, Cheng HY, Ravagnan L, Ferri KF, Zamzami N, Wakeham A, Hakem R, Yoshida H, Kong YY, Mak TW, Zuniga-Pflucker JC, Kroemer G, Penninger JM. Essential role of the mitochondrial apoptosis-inducing factor in programmed cell death. Nature. $2001 ; 410: 549-54$.

Katakowski JA, Palliser D. siRNA-based topical microbicides targeting sexually transmitted infections. Current Opinion in Molecular Therapeutics. 2010;12:192-202.

Keilhoff G, Wolf G. Comparison of double fluorescence staining and LDH-test for monitoring cell viability in vitro. Neuroreport. 1993;5:129-32. 
Kermer P, Klocker N, Bahr M. Neuronal death after brain injury. Models, mechanisms, and therapeutic strategies in vivo. Cell and Tissue Research. 1999;298:383-95.

Kihara AH, Mantovani de Castro L, Belmonte MA, Yan CY, Moriscot AS, Hamassaki DE. Expression of connexins 36, 43, and 45 during postnatal development of the mouse retina. Journal of Neurobiology. 2006;66:1397-410.

Kihara $\mathrm{AH}$, Moriscot AS, Ferreira PJ, Hamassaki DE. Protecting RNA in fixed tissue: an alternative method for LCM users. Journal of Neuroscience Methods. 2005; 148:103-7.

Kihara AH, Paschon V, Akamine PS, Saito KC, Leonelli M, Jiang JX, Hamassaki DE, Britto LR. Differential expression of connexins during histogenesis of the chick retina. Developmental Neurobiology. 2008;68:1287-302.

Kihara AH, Paschon V, Cardoso CM, Higa GS, Castro LM, Hamassaki DE, Britto LR. Connexin36, an essential element in the rod pathway, is highly expressed in the essentially rodless retina of Gallus gallus. The Journal of Comparative Neurology. 2009;512:651-63.

Kihara AH, Santos TO, Osuna-Melo EJ, Paschon V, Vidal KS, Akamine PS, Castro LM, Resende RR, Hamassaki DE, Britto LR. Connexin-mediated communication controls cell proliferation and is essential in retinal histogenesis. International Journal of Developmental Neuroscience : The Official Journal of the International Society for Developmental Neuroscience. 2010;28:39-52.

Kirchhoff F, Dringen R, Giaume C. Pathways of neuron-astrocyte interactions and their possible role in neuroprotection. European Archives of Psychiatry and Clinical Neuroscience. 2001;251:159-69.

Klein JA, Ackerman SL. Oxidative stress, cell cycle, and neurodegeneration. The Journal of Clinical Investigation. 2003;111:785-93.

Koistinaho J, Swanson RA, de Vente J, Sagar SM. NADPH-diaphorase (nitric oxide synthase)-reactive amacrine cells of rabbit retina: putative target cells and stimulation by light. Neuroscience. 1993;57:587-97.

Koizumi A, Zeck G, Ben Y, Masland RH, Jakobs TC. Organotypic culture of physiologically functional adult mammalian retinas. PloS One. 2007;2:e221.

Krantic S, Mechawar N, Reix S, Quirion R. Molecular basis of programmed cell death involved in neurodegeneration. Trends in Neurosciences. 2005;28:670-6.

Kumar NM, Gilula NB. The gap junction communication channel. Cell. 1996;84:3818.

Lampe PD, Lau AF. Regulation of gap junctions by phosphorylation of connexins. Archives of Biochemistry and Biophysics. 2000;384:205-15. 
Lampe PD, Lau AF. The effects of connexin phosphorylation on gap junctional communication. The International Journal of Biochemistry \& Cell Biology. 2004; 36:1171-86.

Leist M, Jaattela M. Four deaths and a funeral: from caspases to alternative mechanisms. Nature Reviews Molecular Cell Biology. 20012:589-98.

Lin JS, Eckert R, Kistler J, Donaldson P. Spatial differences in gap junction gating in the lens are a consequence of connexin cleavage. European Journal of Cell Biology. 1998;76:246-50.

Lo CW. The role of gap junction membrane channels in development. Journal of Bioenergetics and Biomembranes. 1996;28:379-85.

Lockshin RA, Zakeri Z. Caspase-independent cell death? Oncogene. 2004;23:276673.

Lynch DR, Dawson TM. Secondary mechanisms in neuronal trauma. Current Opinion in Neurology. 1994;7:510-6.

Masland RH. The fundamental plan of the retina. Nature Neuroscience. 2001;4:87786.

Medhurst AD, Harrison DC, Read SJ, Campbell CA, Robbins MJ, Pangalos MN. The use of TaqMan RT-PCR assays for semiquantitative analysis of gene expression in CNS tissues and disease models. Journal of Neuroscience Methods. 2000;98:9-20.

Mesnil M, Piccoli C, Tiraby G, Willecke K, Yamasaki H. Bystander killing of cancer cells by herpes simplex virus thymidine kinase gene is mediated by connexins. Proceedings of the National Academy of Sciences of the United States of America. 1996;93:1831-5.

Nagy JI, Rash JE. Connexins and gap junctions of astrocytes and oligodendrocytes in the CNS. Brain Research Reviews. 2000;32:29-44.

Nagy JI, Rash JE. Astrocyte and oligodendrocyte connexins of the glial syncytium in relation to astrocyte anatomical domains and spatial buffering. Cell Communication \& Adhesion. 2003;10:401-6.

Nakase T, Fushiki S, Naus CC. Astrocytic gap junctions composed of connexin 43 reduce apoptotic neuronal damage in cerebral ischemia. Stroke: a Journal of Cerebral Circulation. 2003;34:1987-93.

Nakase T, Naus CC. Gap junctions and neurological disorders of the central nervous system. Biochimica et Biophysica Acta. 2004;1662:149-58.

Naus CC, Bechberger JF, Caveney S, Wilson JX. Expression of gap junction genes in astrocytes and C6 glioma cells. Neuroscience Letters. 1991;126:33-6. 
Naus CC, Ozog MA, Bechberger JF, Nakase T. A neuroprotective role for gap junctions. Cell Communication \& Adhesion. 2001;8:325-8.

Nguyen MD, Mushynski WE, Julien JP. Cycling at the interface between neurodevelopment and neurodegeneration. Cell Death and Differentiation. 2002;9:1294-306.

Orellana JA, Saez PJ, Shoji KF, Schalper KA, Palacios-Prado N, Velarde V, Giaume C, Bennett MV, Saez JC. Modulation of brain hemichannels and gap junction channels by pro-inflammatory agents and their possible role in neurodegeneration. Antioxidants \& Redox Signaling. 2009;11:369-99.

Ozog MA, Siushansian R, Naus CC. Blocked gap junctional coupling increases glutamate-induced neurotoxicity in neuron-astrocyte co-cultures. Journal of Neuropathology and Experimental Neurology. 2002;61:132-41.

Paschon V, Higa GS, Resende RR, Britto LRG, Kihara AH. Blocking of connexinmediated communication promotes neuroprotection during acute degeneration induced by mechanical trauma. PloS One. 2012;9:e45449.

Paschon V, Higa GS, Walter LT, de Sousa E, Zuzarte FC, Weber VR, Resende RR, Kihara $\mathrm{AH}$. A new and reliable guide for studies of neuronal loss based on focal lesions and combinations of in vivo and in vitro approaches. Plos One. 2013;8:e60486.

Prada F, Medina JI, Lopez-Gallardo M, Lopez R, Quesada A, Spira A, Prada C. Spatiotemporal gradients of differentiation of chick retina types I and II cholinergic cells: identification of a common postmitotic cell population. The Journal of Comparative Neurology. 1999;410:457-66.

Rawanduzy A, Hansen A, Hansen TW, Nedergaard M. Effective reduction of infarct volume by gap junction blockade in a rodent model of stroke. Journal of Neurosurgery. 1997;87:916-20.

Rego AC, Oliveira CR. Mitochondrial dysfunction and reactive oxygen species in excitotoxicity and apoptosis: implications for the pathogenesis of neurodegenerative diseases. Neurochemical Research. 2003;28:1563-74.

Rouach N, Avignone E, Meme W, Koulakoff A, Venance L, Blomstrand F, Giaume C. Gap junctions and connexin expression in the normal and pathological central nervous system. Biology of the Cell / Under the Auspices of the European Cell Biology Organization. 2002;94:457-75.

Rozental R, Giaume C, Spray DC. Gap junctions in the nervous system. Brain Research Reviews. 2000;32:11-5.

Saba R, Goodman CD, Huzarewich RL, Robertson C, Booth SA. A miRNA signature of prion induced neurodegeneration. PloS One. 2008;3:e3652. 
Saez JC, Gregory WA, Watanabe T, Dermietzel R, Hertzberg EL, Reid L, Bennett MV, Spray DC. CAMP delays disappearance of gap junctions between pairs of rat hepatocytes in primary culture. The American Journal of Physiology. 1989;257:C111.

Schonrock N, Ke YD, Humphreys D, Staufenbiel M, Ittner LM, Preiss T, Gotz J. Neuronal microRNA deregulation in response to Alzheimer's disease amyloid-beta. PloS One. 2010;5:e11070.

Seigel GM. The golden age of retinal cell culture. Molecular Vision. 1999;5:4.

Sohl G, Willecke K. An update on connexin genes and their nomenclature in mouse and man. Cell Communication \& Adhesion. 2003;10:173-80.

Spray DC, Harris AL, Bennett MV. Voltage dependence of junctional conductance in early amphibian embryos. Science. 1979;204:432-4.

Spray DC, Harris AL, Bennett MV. Gap junctional conductance is a simple and sensitive function of intracellular pH. Science. 1981;211:712-5.

Srinivas M, Hopperstad MG, Spray DC. Quinine blocks specific gap junction channel subtypes. Proceedings of the National Academy of Sciences of the United States of America. 2001;98:10942-7.

Srinivas M, Rozental R, Kojima T, Dermietzel R, Mehler M, Condorelli DF, Kessler JA, Spray DC. Functional properties of channels formed by the neuronal gap junction protein connexin36. The Journal of Neuroscience : the Official Journal of the Society for Neuroscience. 1999;19:9848-55.

Striedinger K, Petrasch-Parwez E, Zoidl G, Napirei M, Meier C, Eysel UT, Dermietzel R. Loss of connexin36 increases retinal cell vulnerability to secondary cell loss. The European Journal of Neuroscience. 2005;22:605-16.

Susin SA, Lorenzo HK, Zamzami N, Marzo I, Snow BE, Brothers GM, Mangion J, Jacotot E, Costantini P, Loeffler M, Larochette N, Goodlett DR, Aebersold R, Siderovski DP, Penninger JM, Kroemer G. Molecular characterization of mitochondrial apoptosis-inducing factor. Nature. 1999;397:441-6.

Takeuchi H, Mizoguchi H, Doi Y, Jin S, Noda M, Liang J, Li H, Zhou Y, Mori R, Yasuoka S, Li E, Parajuli B, Kawanokuchi J, Sonobe Y, Sato J, Yamanaka K, Sobue G, Mizuno T, Suzumura A. Blockade of gap junction hemichannel suppresses disease progression in mouse models of amyotrophic lateral sclerosis and Alzheimer's disease. PloS One. $2011 ; 6:$ e21108.

Theis M, Sohl G, Eiberger J, Willecke K. Emerging complexities in identity and function of glial connexins. Trends in Neurosciences. 2005;28:188-95.

Thoreson WB, Witkovsky P. Glutamate receptors and circuits in the vertebrate retina. Progress in Retinal and Eye Research. 1999;18:765-810. 
Vaney DI. Retinal neurons: cell types and coupled networks. Prog Brain Res. 2002;136:239-54.

Vaney DI, Nelson JC, Pow DV. Neurotransmitter coupling through gap junctions in the retina. The Journal of Neuroscience : the Official Journal of the Society for Neuroscience. 1998;18:10594-602.

Velazquez Perez L, Jara Gonzalez JA, Sanchez Cruz G. [Peripheral nerve conduction studies in patients with multiple organ failure]. Revista de Neurologia. 2003;36:15-20.

Vessey JP, Lalonde MR, Mizan HA, Welch NC, Kelly ME, Barnes S. Carbenoxolone inhibition of voltage-gated $\mathrm{Ca}$ channels and synaptic transmission in the retina. Journal of Neurophysiology. 2004;92:1252-6.

Vidal L, Diaz F, Villena A, Moreno M, Campos JG, Perez de Vargas I. Reaction of Muller cells in an experimental rat model of increased intraocular pressure following timolol, latanoprost and brimonidine. Brain Res Bull. 2010;82:18-24.

Wassle $\mathrm{H}$, Boycott BB. Functional architecture of the mammalian retina. Physiological Reviews. 1991;71:447-80.

Watanabe A. The interaction of electrical activity among neurons of lobster cardiac ganglion. The Japanese Journal of Physiology. 1958;8:305-18.

Willecke K, Eiberger J, Degen J, Eckardt D, Romualdi A, Guldenagel M, Deutsch U, Sohl G. Structural and functional diversity of connexin genes in the mouse and human genome. Biological Chemistry. 2002;383:725-37.

Witkovsky $\mathrm{P}$, Schutte M. The organization of dopaminergic neurons in vertebrate retinas. Visual Neuroscience. 1991;7:113-24.

Yeager M, Nicholson BJ. Structure of gap junction intercellular channels. Current Opinion in Structural Biology. 1996;6:183-92.

Zahs KR, Kofuji P, Meier C, Dermietzel R. Connexin immunoreactivity in glial cells of the rat retina. The Journal of Comparative Neurology. 2003;455:531-46.

Zigmond MJ. Promoting responsible conduct: striving for change rather than consensus. Commentary on "Ambiguity, trust, and the responsible conduct of research" (F. Grinnell). Science and Engineering Ethics. 1999;5:219-28.

Zigmond MJ, Bloom FE, Landis SC, Roberts JL, Squire LR. Fundamental neuroscience. San Diego: Academic Press; 1999. p. 317-26. 


\section{APÊNDICE A}

Artigo publicado na PloS one 8:e60486. "A new and reliable guide for studies of neuronal loss based on focal lesions and combinations of in vivo and in vitro approaches." de autoria de Paschon V, Higa GS, Walter LT, de Sousa E, Zuzarte FC, Weber VR, Resende RR, Kihara AH (2013) 


\section{APÊNDICE B}

Artigo publicado na PloS one 9:e45449. "Blocking of connexin-mediated communication promotes neuroprotection during acute degeneration induced by mechanical trauma." de autoria de Paschon V, Higa GS, Resende RR, Britto LRG, Kihara AH (2012). 


\section{APÊNDICE C}

Artigo publicado no journal of the International Society for Developmental

Neuroscience 28:39-52. "Connexin-mediated communication controls cell proliferation and is essential in retinal histogenesis." de autoria de Kihara AH, Santos TO, Osuna-Melo EJ, Paschon V, Vidal KS, Akamine PS, Castro LM, Resende RR, Hamassaki DE, Britto LR (2010) 